University of South Florida

DIGITAL COMMONS

Digital Commons @ University of

@ UNIVERSITY OF SOUTH FLORIDA

South Florida

4-15-1992

\title{
Simulation of the 1979 Spring Bloom in the Mid-Atlantic Bight: A Coupled Physical/Biological/Optical Model
}

Watson W. Gregg

University of South Florida

John J. Walsh

University of South Florida, jwalsh@marine.usf.edu

Follow this and additional works at: https://digitalcommons.usf.edu/msc_facpub

Part of the Marine Biology Commons

\section{Scholar Commons Citation}

Gregg, Watson W. and Walsh, John J., "Simulation of the 1979 Spring Bloom in the Mid-Atlantic Bight: A Coupled Physical/Biological/Optical Model" (1992). Marine Science Faculty Publications. 72.

https://digitalcommons.usf.edu/msc_facpub/72

This Article is brought to you for free and open access by the College of Marine Science at Digital Commons @ University of South Florida. It has been accepted for inclusion in Marine Science Faculty Publications by an authorized administrator of Digital Commons @ University of South Florida. For more information, please contact digitalcommons@usf.edu. 


\title{
Simulation of the 1979 Spring Bloom in the Mid-Atlantic Bight: A Coupled Physical/Biological/Optical Model
}

\author{
WATSON W. GREGG' aND JOHN J. WaLSH
}

Department of Marine Science, University of South Florida, St. Petersburg

\begin{abstract}
A coupled physical/biological/optical model was developed to investigate the causes of phytoplankton variability in the spring 1979 Mid-Atlantic Bight (MAB) as observed in Coastal Zone Color Scanner (CZCS) imagery, and to estimate the magnitude and variability of primary production. The model incorporated advection, mixing, sinking, growth as a function of light, temperature, and nutrient availability, and death as a function of ingestion. These variables were assumed to determine the large-scale, low-frequency variability of phytoplankton distributions. The model also contained two phytoplankton groups, netplankton and nanoplankton, which differed in maximum growth rate, sinking rate, and specific light absorption. The model produced chlorophyll concentrations within the first attenuation depth within 1 standard deviation of CZCS imagery on large scale (i.e., over regions about $50 \mathrm{~km}$ in width). This suggested the model represented the physical/biological coupling often observed in imagery. The two phytoplankton groups used in the model were initialized to equal distributions throughout the model domain and organized in the course of the model run into distributions corresponding to long-term observations in the MAB; netplankton dominated the coast and nanoplankton dominated the slope. This suggested that the model incorporated the mechanisms causing these distributions in the real ocean, namely, the interaction between mixing, differential growth rates, and differential sinking rates. Finally, primary production estimates were within reasonable agreement with those measured in situ, suggesting the applicability of the model in estimating regional-scale primary production.
\end{abstract}

\section{INTRODUCTION}

\subsection{Background}

Chlorophyll estimates from Coastal Zone Color Scanner (CZCS) imagery have revealed a temporal and spatial variability greater than previously realized. Understanding these chlorophyll distributions and their causes is critical for estimating the magnitude and variability of oceanic primary production, which may have significant impact on global climate. Utilizing CZCS data in the development, initialization, and validation of ecosystem simulation models can potentially provide this fuller understanding and increase the confidence of estimates of primary production.

Recent efforts by Walsh et al. [1988], Wroblewski [1989], and Ishizaka [1990] have adopted this approach with considerable success. Wroblewski's [1989] model of the North Atlantic was a climatological representation in one dimension (time) over many points. Advection processes were not included, but vertical mixing was. Wroblewski showed that the major features of the spring bloom in the North Atlantic as seen in CZCS composites could be related to the latitudeand time-dependent solar energy input. Ishizaka's [1990] research coupled biological processes with a circulation field interpolated from a current meter array in the southeastern U.S. continental shelf for April 1980. This model applied only at the depth of the meters, $\approx 17 \mathrm{~m}$, and consequently was unable to resolve vertical processes. Nevertheless, his results showed the importance of horizontal advection in determining the distribution of chlorophyll observed in a

\footnotetext{
${ }^{1}$ Now at NASA Goddard Space Flight Center, Greenbelt, Maryland.

Copyright 1992 by the American Geophysical Union.

Paper number 91JC03057. 0148-0227/92/91JC-03057\$05.00
}

time series of CZCS imagery. Walsh et al. [1988] developed a coupled four-dimensional physical/biological model of the Mid-Atlantic Bight shelf ecosystem. His results also showed the importance of physical events (wind-driven mixing and upwelling) on chlorophyll distributions.

We attempt here to continue and extend these research efforts by developing a numerical simulation model of the Mid-Atlantic Bight (MAB) shelf/slope ecosystem. The model most closely follows that of Walsh et al. [1988] in that it is a coupled four-dimensional physical/biological model. It extends previous efforts in at least four distinct ways: (1) The model includes the MAB slope region, extending to the 2000 $\mathrm{m}$ isobath; (2) the model includes both nitrate and regenerated ammonium in order to quantify total primary production, instead of "new" production based only on nitrate uptake; (3) the model includes two phytoplankton groups, netplankton and nanoplankton, which differ in maximum growth rate, sinking rate, and specific light absorption; and (4) the model determines the spectral transmittance of irradiance through the atmosphere and ocean to produce a more realistic description of the light available for phytoplankton growth than the nonspectral calculations used previously. Irradiance transmittance through the atmosphere and oceans has a strong spectral dependence, and neglecting this dependence can result in miscalculation of the light at depth, thus affecting primary production estimates. The model is intended to incorporate the dominant physical, biological, and optical processes of the phytoplankton dynamical system.

Testing and evaluation of the coupled physical/biological/ optical model is performed by direct comparison with CZCS estimates of chlorophyll. The model grid is in rectilinear coordinates (Figure 1) beginning at the $10 \mathrm{-m}$ isobath and ending at the $2000-\mathrm{m}$ isobath (edge of slope), with exact grid point spacing of four remapped CZCS pixels $(\approx 5 \mathrm{~km})$. The model has 10 vertical layers, each layer $H / 10$, where $H$ is the bottom depth on the shelf and $200 \mathrm{~m}$ (the pycnocline depth) 


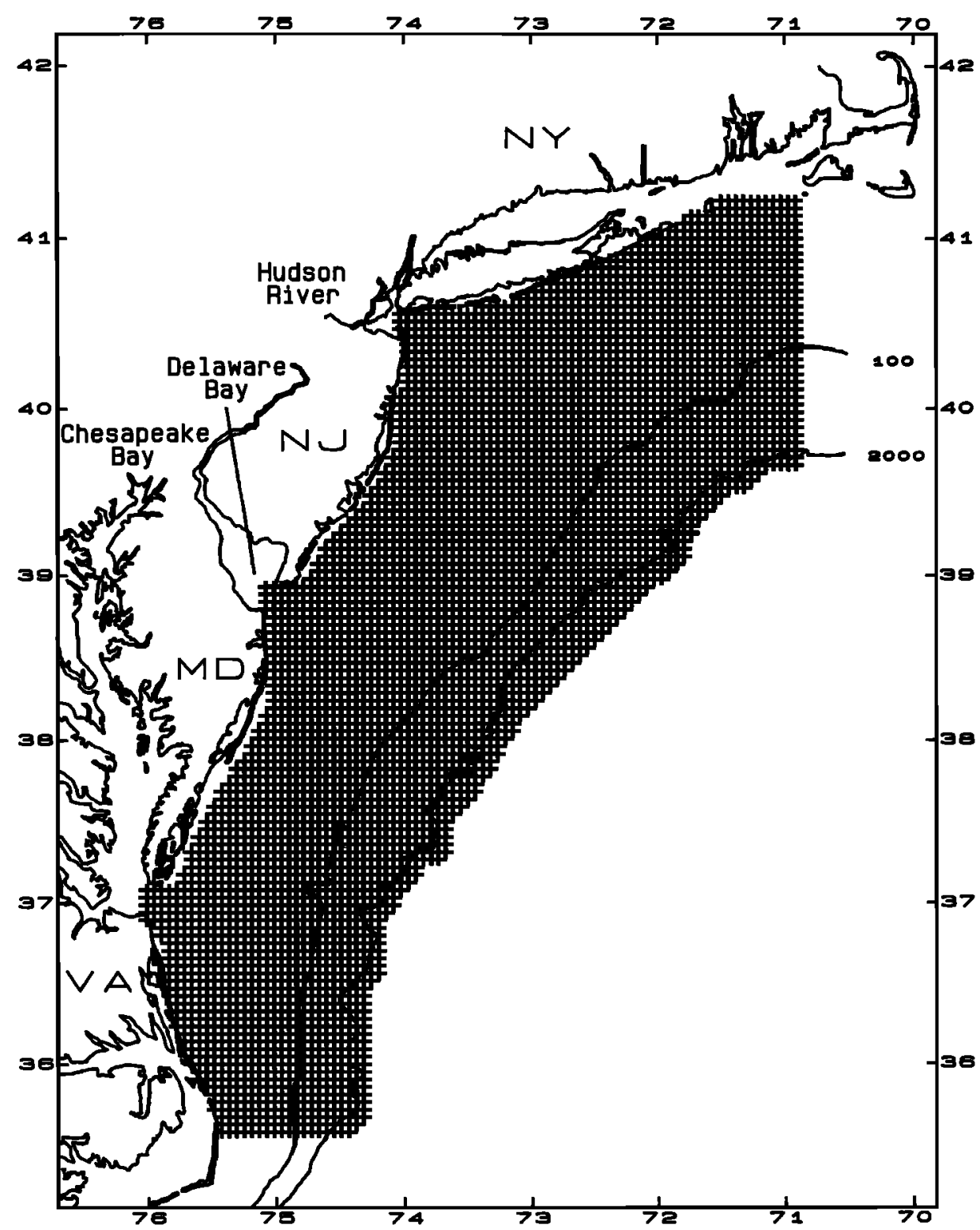

Fig. 1. Map of the Mid-Atlantic Bight, U.S. east coast, over which model grid points are shown. Long Island is located in the center of figure at $41^{\circ} \mathrm{N}$. The Hudson estuary, Delaware Bay, and Chesapeake Bay are located at the coast, in order from north to south. The $100-\mathrm{m}$ and $2000-\mathrm{m}$ isobaths are labeled.

on the slope. Chlorophyll concentrations are averaged over the first attenuation depth $\left(=1 / K_{d}\right.$, where $K_{d}$ is the downwelling attenuation coefficient) prior to comparison with CZCS imagery. This allows an unbiased comparison with CZCS imagery, which is effectively the mean chlorophyll within the first attenuation depth [Gordon and $\mathrm{Mc}$ Cluney, 1975]. The downwelling attenuation coefficient at $520 \mathrm{~nm}$ was used to determine these depths, following Gordon et al. [1983]. Thus the model provides an unbiased attenuation depth correspondence with the imagery.

\subsection{Mid-Atlantic Bight}

The Mid-Atlantic Bight is a synoptic scale, continental shelf/slope region located between approximately $35^{\circ}$ and $42^{\circ} \mathrm{N}$ latitude and $70^{\circ}$ and $77^{\circ} \mathrm{W}$ longitude (Figure 1). The model grid space comprises an area $635 \mathrm{~km}$ long and $450 \mathrm{~km}$ wide, for a total area of $2.9 \times 10^{5} \mathrm{~km}^{2}$. The region is sufficiently large to include several distinct geophysical/ ecological/optical subregions, i.e., coast (bottom depth $D \leq$ $30 \mathrm{~m})$, mid-shelf $(30 \mathrm{~m}<D \leq 60 \mathrm{~m})$, outer shelf $(60 \mathrm{~m}<$ $D \leq 200 \mathrm{~m})$, and slope $(D>200 \mathrm{~m})$. The primary difference among these regions is the bottom depth, but they also differ in circulation dynamics [Beardsley and Boicourt, 1981], external influences (e.g., estuaries), phytoplankton species composition [Malone et al., 1983a], and optically active substances.

\section{COUPled Model}

\subsection{Governing Equations}

We assume that, to first order, the large-scale (mesoscale), low-frequency (subtidal) features of the MAB spring bloom 
may be described by a system of equations comprising mixing, advection, sinking, growth as a function of light, temperature, and nutrient availability, and death by ingestion. This assumption leads to a set of coupled, partial differential equations called the governing equations of the ecosystem simulation analysis,

$$
\begin{gathered}
\frac{\partial}{\partial t} C_{t}=A \nabla^{2} C_{t}-\nabla \cdot C_{i} \mathbf{v}-\nabla \cdot C_{i}\left(\mathbf{w}_{s}\right)_{i} \\
+C_{t} \mu_{i}\left(E_{d}(\lambda, z), T, \sum_{k} N_{k}\right)-\gamma_{i} C_{i} \\
\frac{\partial}{\partial t} N_{k}=A \nabla^{2} N_{k}-\nabla \cdot N_{k} \mathbf{v}-b \sum_{i} C_{i} \mu_{l}\left(E_{d}(\lambda, z) T, N_{k}\right) \\
+\varepsilon_{k} b \gamma \sum_{i} C_{l}
\end{gathered}
$$

where the subscripts denote the existence of discrete quantities of nutrients ( $N$, as nitrate and ammonium) and chlorophyll ( $C$, as netplankton and nanoplankton), the boldface characters denote vector quantities, and

$A$ kinematic eddy diffusion coefficient for three dimensions $\left(\mathrm{cm}^{2} \mathrm{~s}^{-1}\right)$;

$b$ nitrogen/chlorophyll ratio, equal to 0.5 ( $\mu \mathrm{g}$ atoms $\left.\mathrm{N} \mu \mathrm{g}^{-1}\right)$;

$E_{d}(\lambda)$ downwelling spectral irradiance $\left(\mathrm{W} \mathrm{m}^{-2} \mathrm{~nm}^{-1}\right)$;

$T$ temperature $\left({ }^{\circ} \mathrm{C}\right)$;

V vector velocity $\left(\mathrm{cm} \mathrm{s}^{-1}\right)$;

$\mathbf{w}_{s}$ vector sinking rate of phytoplankton $\left(\mathrm{m} \mathrm{d}^{-1}\right)$;

$\nabla$ gradient operator;

$\nabla^{2}$ Laplacian operator;

$\gamma$ ingestion rate of chlorophyll by herbivores $\left(\mathrm{d}^{-1}\right)$;

$\varepsilon$ nutrient excretion rate by herbivores $\left(d^{-1}\right)$;

$\mu$ specific growth rate of phytoplankton as a function of light, temperature and nutrient availability $\left(d^{-1}\right)$.

The first term on the right-hand side in (1) and (2) is the diffusion term, the second term accounts for advection, the third in (1) only is sinking (which does not apply to dissolved nutrients, and also goes to zero in the horizontal), and the remaining terms are the biological processes terms. To solve this set of equations, one requires four separate models to obtain numerical values for the variables. These are a physical circulation model to obtain advection, mixing, and sinking; an atmospheric radiative transfer model to obtain spectral irradiance just below the sea surface; an oceanic radiative transfer model to obtain the available spectral irradiance at depth; and a biological processes model to derive growth of phytoplankton resulting from the calculated light field, temperature, and nutrient assimilation, and death resulting from grazing and other ingestion.

The circulation model determines the time-dependent horizontal and vertical motions of nutrients and phytoplankton. The radiative transfer models determine the availability of spectral irradiance in the water column at high resolution (10 $\mathrm{nm}$ ) as a function of attenuation by atmospheric and oceanic constituents. The biological model determines the growth of phytoplankton as a function of the distribution of nutrients and availability of light, and determines death as a function of ingestion. Maximum growth rates are also temperaturedependent, and temperatures increase both seaward and over the spring.

For all models we assume that a pycnocline exists at $200 \mathrm{~m}$ on the slope region [Csanady and Hamilton, 1988]. We also assume that the phytoplankton assemblage of the spring MAB can be characterized by two groups, netplankton with diameter $>20 \mu \mathrm{m}$ and nanoplankton with diameter $<20 \mu \mathrm{m}$ [Malone, 1982; Marshall and Cohn, 1987], which differ in maximum growth rates (netplankton grow faster), light saturation intensities (nanoplankton saturate faster), specific absorption coefficients (higher for nanoplankton), and sinking rates (netplankton sink at $10 \mathrm{~m} \mathrm{~d}^{-1}$ and nanoplankton at $0.5 \mathrm{~m} \mathrm{~d}^{-1}$ ).

\subsection{Constituent Transport Model}

The constituent transport model describes the fourdimensional $(x, y, z, t)$ motion of phytoplankton, nitrate, and ammonium. It involves the processes of advection, diffusion, and sinking. The portion of the transport model that determines advection and horizontal diffusion is quasitransient, in that solutions to the steady state linear transport equations, expressed as a vorticity balance, proceed in time using mean wind stress over wind event periods (3-15 days). The 1979 spring was divided into 20 steady wind event periods from February through May. The periods ranged in length from 3 to 15 days and in mean scalar wind stress from 0.27 to $1.26 \mathrm{dyn} \mathrm{cm}^{-2}$. This corresponded to a vertical eddy viscosity of $15-69 \mathrm{~cm}^{2} \mathrm{~s}^{-1}$, using Csanady's [1976] formulation. Most of the energy for net substance transport is on this time scale [Han et al., 1980].

The circulation model for the MAB is derived from the friction-driven, linear transport equations at steady state, and is expressed by

$\left\{\frac{\partial \psi}{\partial x} \frac{\partial}{\partial y} \frac{f}{H}-\frac{\partial \psi}{\partial y} \frac{\partial}{\partial x} \frac{f}{H}\right\}+\operatorname{curl}_{z}\left(\tau^{d} / H\right)=\operatorname{curl}_{z}\left(\tau^{s} / H\right)$

where $\tau^{d}$ is bottom stress, $\tau^{s}$ is wind stress, $f$ is the Coriolis parameter, and $H$ is layer thickness, which equals the bottom depth on the shelf and the depth of no motion on the slope (the 200-m pycnocline), assuming, following Csanady and Hamilton [1988] that interface displacements are small relative to the layer thickness. Here, $\psi$ is the transport stream function, defined by

$$
\begin{gathered}
U=-\frac{\partial \psi}{\partial y} \\
V=\frac{\partial \psi}{\partial x}
\end{gathered}
$$

where $U$ and $V$ are the horizontal mass transports (integral of velocities over depth). The fluid is assumed hydrostatic and Boussinesq.

The first two terms on the left-hand side of (3) represent the Jacobian of $\psi, f / H$, so we may simplify to

$$
J(\psi, f / H)+\operatorname{curl}_{z}\left(\tau^{d} / H\right)=\operatorname{curl}_{z}\left(\tau^{s} / H\right)
$$

where $J$ indicates the Jacobian operator. The Jacobian represents the geostrophic portion of the flow, while the curl of the wind and bottom stress components divided by $H$ 
represent the friction-driven portions of the flow. This description is functionally similar to that of Hopkins and Dieterle [1983, 1986], except that we have used a stream function derivation to enforce the no-normal flux condition at the coastal boundary while maintaining a Cartesian coordinate system suitable for application to remapped satellite data, and we have extended the model into the slope region including a 200-m pycnocline.

In (3), $\tau^{s}$ is estimated from the wind velocity, taken from National Climatic Data Center data for John F. Kennedy Airport in New York. Hopkins and Dieterle [1986] effect a solution for $\tau^{d}$ by expressing flow in the complex plane,

$$
\tau^{d}=r_{d} q_{d}
$$

where $r_{d}$ is the bottom or interfacial resistance coefficient and $q_{d}$ is the complex flow at the bottom. Here, $r_{d}$ is taken to be $0.1 \mathrm{~cm} \mathrm{~s}^{-1}$ for the bottom on the shelf [Hopkins and Dieterle, 1983] and $0.025 \mathrm{~cm} \mathrm{~s}^{-1}\left(r_{d}\right.$ on the shelf divided by 4) for interfacial stress on the slope [Johnson, 1987].

2.2.1. Boundary conditions. The no-normal flux condition at the coast is enforced by making the coast a streamline $\left(\psi=\psi_{c}\right)$, except at estuaries where a specified inflow typical of spring conditions is imposed. These are $2.13 \times 10^{3}$ $\mathrm{m}^{3} \mathrm{~s}^{-1}$ for the Hudson River, $1.69 \times 10^{3} \mathrm{~m}^{3} \mathrm{~s}^{-1}$ for the Delaware Bay, and $9.88 \times 10^{3} \mathrm{~m}^{3} \mathrm{~s}^{-1}$ for the Chesapeake Bay. For the downstream (southern) boundary condition, we make the assumption that $\partial^{2} \psi / \partial y^{2}=0$. The offshore boundary, at the $2000-\mathrm{m}$ isobath, is set to an arbitrary constant, $\psi=0 \mathrm{~m}^{3} \mathrm{~s}^{-1}$. For the upstream boundary we take advantage of a moored current meter array placed for the Nantucket Shoals Flux Experiment in 1979-1980 [Beardsley et al., 1985].

2.2.2 Three-dimensional circulation. The transport stream function may be deconvolved into velocities at any depth, expressed as the complex flow $q(z)$, using the Hopkins and Slatest [1986] model. This model resolves the surface Ekman, geostrophic interior, and bottom (or interfacial) Ekman components of the transport. We solve for $q(z)$ over 10 layers in the vertical, each layer $H / 10$, for each wind event, where the vertical kinematic eddy viscosity $A_{z}$ is taken from Csanady [1976], using the mean scalar wind stress for each event. $A_{z}$ is assumed constant throughout the water column except at the slope pycnocline, where it is set to 0.01 times its value at the surface.

Once the horizontal velocities are known for each layer, $w(z)$ is obtained by integrating the equation of continuity

$$
-\frac{\partial w}{\partial z}=\frac{\partial u}{\partial x}+\frac{\partial v}{\partial y}
$$

assuming kinematic boundary conditions at both the surface and bottom/interface. With the depth-dependent horizontal and vertical velocities in place, we now have the full, wind event scale three-dimensional circulation. The circulation fields are then used to compute the advection of biological constituents.

2.2.3. Diffusion. Horizontal diffusion is implicit in the advection calculation. However, we explicitly compute vertical eddy diffusivity (assumed equal to viscosity) from the steady wind stress [Csanady, 1976]. As with eddy viscosity, $A_{z}$ is vertically constant except at the 200 -m pycnocline on the slope, where we set $A_{z}$ to 0.01 times its value at the surface to reduce diffusive flux across the interface.
2.2.4. Sinking. Aas [1981] tabulated the densities of various phytoplankton groups based on cell structural materials and water content. Using his values, we computed a density contrast of 0.2 for diatoms and 0.06 for other groups using a mean density for seawater of $1.031 \mathrm{~g} \mathrm{~cm}^{-3}$. If one assumes the mean radius of the two size fractions of phytoplankton used in this study as 25 and $5 \mu \mathrm{m}$ for netplankton and nanoplankton, respectively, one computes sinking rates of $\approx 25$ and $0.3 \mathrm{~m} \mathrm{~d}^{-1}$, respectively, from Aas' [1981] data. Based on this information, we specified sinking rates $\left(s_{s}\right)$ of 10 and $0.5 \mathrm{~m} \mathrm{~d}^{-1}$, respectively, for netplankton and nanoplankton. Thus, the sinking rates used here may be considered reasonable, perhaps even conservative, for the specified size ranges of the phytoplankton groups.

The value of $w_{s}$ is prescribed as 0 at the surface and bottom boundaries on the shelf to enforce mass conservation. On the slope, however, particles are allowed to escape the model domain via sinking.

\subsection{Atmospheric Radiative Transfer Model}

The atmospheric radiative transfer model [Gregg and Carder, 1990] computes spectral irradiance just below the sea surface at high resolution $(10 \mathrm{~nm})$ for cloudless maritime skies as a function of atmospheric optical constituents (e.g., ozone, water vapor, aerosols, oxygen) and reflectance at the air/sea interface. The model computes spectral irradiance in the range $350-700 \mathrm{~nm}$, i.e., within the range required for photosynthetically available radiation (PAR) calculations, and hence in the range important for phytoplankton growth. The irradiance was computed at the center point of each of 124 zonal rows of grid points from sunrise to sunset. The surface irradiance was multiplied by 0.63 to account for clouds, based on a 10-year climatological record at Upton, New York [Nagle, 1978].

\subsection{Oceanic Radiative Transfer Model}

The oceanic irradiance transmittance model computes the availability of spectral irradiance in the water column, again at high resolution $(10 \mathrm{~nm})$. Irradiance is spectrally attenuated in the water column as a function of spectral absorption by seawater, phytoplankton (divided into netplankton and nanoplankton fractions), detritus, and gelbstoff.

Radiative transfer through the ocean for downwelling irradiance may be described by Beer-Lambert's law,

$$
E_{d}(\lambda, z)=E_{d}\left(\lambda, 0^{-}\right) \exp \left[-\int K_{d}(\lambda, z) d z\right]
$$

where $E_{d}\left(\lambda, 0^{-}\right)$is the downwelling spectral irradiance just below the sea surface and $K_{d}(\lambda, z)$ is the downwelling attenuation coefficient. In keeping with the assumption that two phytoplankton groups represent the MAB shelf/slope system, we expand Smith and Baker's [1978] formulation of diffuse attenuation to include separate contributions from the two phytoplankton fractions, detritus, and gelbstoff,

$$
\begin{aligned}
K_{d}(\lambda, z)=K_{w}(\lambda)+\sum( & \left.k_{c}\right)_{i}(\lambda) C_{i}(z) \\
& +k_{p h}(\lambda) P h(z)+K_{g}(\lambda)
\end{aligned}
$$

where $K_{w}(\lambda)$ represents the spectral attenuation coefficient of pure seawater, $\left(k_{c}\right)_{i}(\lambda)$ represents the specific spectral 
attenuation coefficient for each phytoplankton group, $C_{i}(z)$ is the concentration of each group with depth, $k_{p h}(\lambda)$ represents the specific spectral attenuation coefficient for detritus (as represented by phaeopigments), $\operatorname{Ph}(z)$ is the concentration of phaeopigments, and $K_{g}(\lambda)$ represents the spectral attenuation coefficient of gelbstoff.

$K_{w}(\lambda)$ was taken from Baker and Smith [1982]. We derived detrital absorption from Kiefer and SooHoo's [1982] observations as

$$
a_{p h}(\lambda)=0.0843 \exp [-0.007(\lambda-400)] .
$$

We assumed that the total detrital absorption coefficient could be related to the phaeophytin concentration, which we took to be $0.15 \mathrm{C}$, based on analysis of data from the Atlantic Coastal Experiment, 1979 (ACE V) [von Bock, 1983a]. We further assumed that $a_{p h} \approx k_{p h}$.

Normalized (to maximum absorption) spectral-specific absorption curves for netplankton and nanoplankton, assuming netplankton are dominated by diatoms and nanoplankton by chlorophytes, were taken from Sathyendranath et al. [1987]. These normalized curves were fitted to observed $k_{c \text { PAR }}$ values [Campbell and $O^{\prime}$ Reilly, 1988] to obtain $k_{c}(\lambda)$ values for each phytoplankton group for the spring MAB. Thus we retain spectral dependence appropriate for each group, and simultaneously match observed spectral attenuation by phytoplankton in the MAB. A higher $k_{c \mathrm{PAR}}$ for nanoplankton $\left(0.0130\right.$ to $0.0108 \mathrm{~m}^{2} \mathrm{mg}$ chlorophyll ${ }^{-1}$ for netplankton) reflects the so-called "package effect" of small phytoplankton [Campbell and O'Reilly, 1988].

Using light extinction data in the MAB for March 1979 from ACE V data [von Bock, 1983a], we computed residual attenuation after accounting for water, phytoplankton, and detritus. We assumed all residual extinction was due to gelbstoff, and used Bricaud et al.'s [1981] expression for the normalized specific absorption coefficient of gelbstoff $\left[a_{g}^{*}\right]_{N}(\lambda)$. Letting $K_{g}(\lambda)=G\left[a_{g}^{*}\right]_{N}(\lambda)$, we could determine $G$ iteratively from the $1 \%$ light depth. $G$ is related to the gelbstoff concentration, but includes other residual effects such as the average cosine and the presence of other optical constituents. The data were divided into four regions prior to the iteration, and $G$ was computed for each region separately. We did not allow vertical variation of $G$.

\subsection{Biological Model}

The biological model describes the processes of growth and death of phytoplankton, and of uptake and excretion of nutrients. Growth is determined as a function of light availability, temperature, and nutrient availability. Lightdependent growth is determined by Steele's [1962] model, which includes the effects of photoinhibition based on the intensity at which light saturation occurs for phytoplankton. These light saturation intensities differ for each phytoplankton group, such that nanoplankton approach maximum growth rate $\mu_{m}$ faster than netplankton, but exhibit a greater photoinhibition effect. Steele's model is also modified to include a temperature and phytoplankton group dependence, based on observations by Malone [1982]. In this formulation, netplankton have higher maximum growth rates than nanoplankton at the same temperature.

Nutrient availability (as nitrate and ammonium) is determined from the Monod uptake model. We enforce preferential uptake of ammonium over nitrate. While nitrate is
TABLE 1. Initial Conditions for Nitrate $\left(\mathrm{NO}_{3}\right)$, Ammonium $\left(\mathrm{NH}_{4}\right)$, Netplankton, and Nanoplankton on February 28,1979 , the Initialization Date of the Model

\begin{tabular}{|c|c|c|c|c|}
\hline & $\begin{array}{c}\mathrm{NO}_{3}, \\
\mu \mathrm{g} \text { at. } \\
\mathrm{L}^{-1}\end{array}$ & $\begin{array}{c}\mathrm{NH}_{4}, \\
\mu \mathrm{g} \text { at. } \\
\mathrm{L}^{-1}\end{array}$ & $\begin{array}{l}\text { Netplankton, } \\
\text { mg m }^{-3}\end{array}$ & $\begin{array}{c}\text { Nanoplankton, } \\
\mathrm{mg} \mathrm{m}^{-3}\end{array}$ \\
\hline Interior & 6 & 0.5 & CZCS & CZCS \\
\hline Upstream & 6 & 0.5 & CZCS & CZCS \\
\hline Downstream & 6 & 0.5 & CZCS & CZCS \\
\hline Slope & 6 & 0.5 & CZCS & CZCS \\
\hline Slope pycnocline & 15 & 0.1 & 0.1 & 0.1 \\
\hline \multicolumn{5}{|l|}{ Estuaries } \\
\hline Hudson River & 10 & 10 & 7.5 & 1.5 \\
\hline Delaware Bay & 1 & 1 & 5 & 1 \\
\hline $\begin{array}{l}\text { Chesapeake } \\
\text { Bay }\end{array}$ & 1.3 & 1 & 3 & 0.6 \\
\hline
\end{tabular}

established as an unreplenished pool without sources (except at boundaries), ammonium is allowed to reenter the model internally by regeneration as a function of ingestion of phytoplankton. We set the value of regeneration to $0.6 \gamma C_{i}$.

Ingestion losses are estimated a priori using the formulation of Walsh et al. [1988]. Regional differences are included in this formulation, as suggested by observations [Dagg and Turner, 1982]. Ingestion losses increase only slowly (and nearly linearly) through the spring on the coast and midshelf as a function of daylength, and are approximated by an exponential function (again of daylength) on the outer shelf and slope. Slope ingestion is double the outer shelf rate because temperature observations showed that the slope was nearly $10^{\circ} \mathrm{C}$ warmer than the shelf in spring 1979 . We allow ingestion only during nighttime in the upper nine layers to simulate the vertical migration of herbivores. Ingestion occurs throughout the day in the bottom layer to simulate benthic ingestion, except on the slope.

\subsection{Initial Conditions}

Initial conditions for all substances are shown in Table 1. Chlorophyll initial conditions were obtained from CZCS orbit 1761, February 28, 1979 (the initialization date of the model). Chlorophyll was divided equally between netplankton and nanoplankton. Initial boundary conditions for chlorophyll were the mean within the four major regions of the MAB for upstream, downstream, and the slope offshore boundaries. Initial conditions for all substances in the estuaries were taken from spring measurements at the mouths of the estuaries for 1982 (T. E. Whitledge, personal communication, 1986). For all constituents, the initial distributions were assumed homogeneous with depth.

After initialization, boundary conditions along the upstream, downstream, and slope offshore boundary were changed daily to the means within regions of each constituent. The estuarine and slope pycnocline boundary conditions were kept constant throughout the model run from February 28 to May 8, 1979.

\section{Results}

\subsection{Circulation Model}

Two examples of depth-averaged flow fields are depicted in Figure 2, corresponding to northeast and west-northwest wind events. The flow resulting from the NE wind (generally 

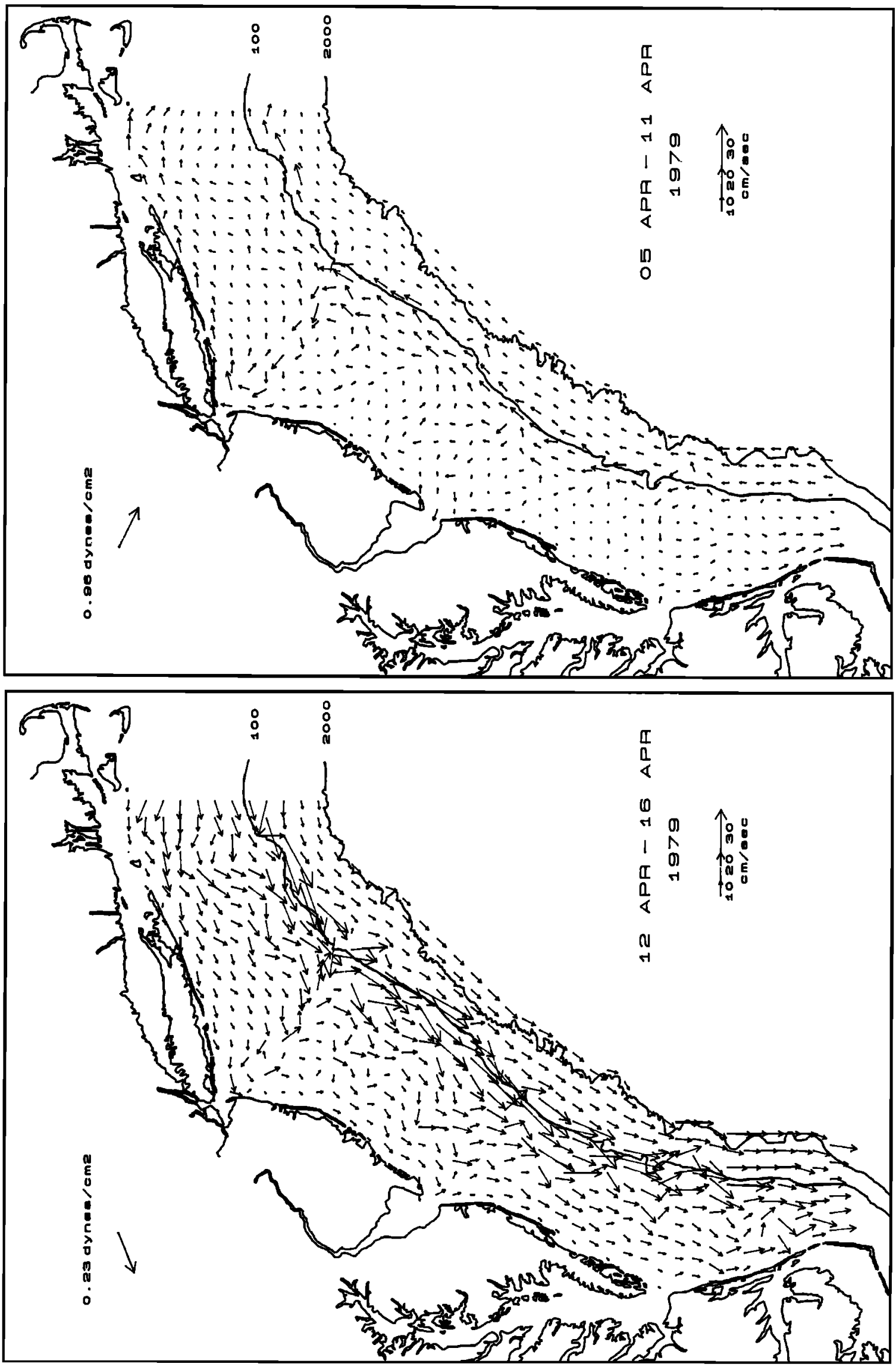

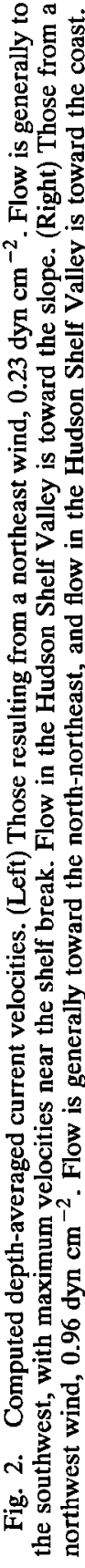


to the south-southwest) is typical for the MAB. The W-NW wind produced a reversal in the current flow along the shelf break and coast. Bathymetric variability is apparent, especially with respect to the Hudson Shelf Valley (HSV, located southeast of the Hudson River), in which the flow reverses for the two wind events shown.

We computed mean layer current velocities (transport within each of the 10 layers divided by the thickness of the layer) for each of the 20 spring 1979 steady periods. An example is shown for surface and bottom layers in Figure 3 corresponding to the W-NW wind seen earlier. An offshore surface flow at the coast and an onshore bottom flow in this case led to an upwelling coastal circulation.

A system of moorings containing current meters from the Marine Ecosystems Analysis Program (MESA) project in 1979 was available for validation of the model-computed depth-dependent current velocities. The meter records were low-pass filtered to remove tidal influences and averaged over the steady wind event periods. For the entire spring, computed velocities were within $1.95 \mathrm{~cm} \mathrm{~s}^{-1}$ speed and $34.2^{\circ} \mathrm{T}$ direction.

\subsection{Oceanic Irradiance Transmittance Model}

The importance of the spectral transmittance model described here was determined by comparison to a nonspectral model. The nonspectral model used for comparison was derived from (10) with $\lambda$ dependence no longer needed. Nonspectral $\left(k_{c}\right)_{i}$ values for each phytoplankton group were taken directly from Campbell and O'Reilly [1988], and the remaining attenuation was computed as the residual from the same $1 \%$ light depths of the ACE V data stations. Thus the nonspectral model produced equivalent total irradiance (expressed as microeinsteins $\left.(\mu \mathrm{E}) \mathrm{m}^{-2} \mathrm{~s}^{-1}\right)$ in each of the four regions at the $1 \%$ light depth as the spectral model. This allowed a fair comparison of the two models.

The nonspectral model produced more total irradiance at shallow depths than the spectral model and less at greater depths (Figure 4) for all regions. The nonspectral model most overestimated irradiance on the slope $\left(+160 \mu \mathrm{E} \mathrm{m}^{-2} \mathrm{~s}^{-1}\right.$ at $7 \mathrm{~m})$ and most underestimated it on the outer shelf $(-38 \mu \mathrm{E}$ $\mathrm{m}^{-2} \mathrm{~s}^{-1}$ at $\left.17 \mathrm{~m}\right)$. The nonspectral model greatly overestimated the spectral model at shallow depths for high chlorophyll concentrations $\left(5 \mathrm{mg} \mathrm{m}^{-3}\right.$, evenly distributed between netplankton and nanoplankton), and greatly underestimated it at large depths for low concentrations $\left(0.5 \mathrm{mg} \mathrm{m}^{-3}\right.$, evenly distributed).

\subsection{Comparison of Model Results With CZCS Imagery}

Eleven CZCS images were available for February 28 through May 8, 1979. The images were averaged over four-by-four pixels, producing a direct match to the model horizontal grid spacing.

Means of model-computed first attenuation depth chlorophyll within regions were within 1 standard deviation of the CZCS means, except on the coast (Figure 5). In general, trends of chlorophyll across regions from coast to slope were similar in both the model and CZCS imagery, the coast having the greatest biomass and the midshelf the second highest. However, the model computed slightly higher biomass on the slope than on the outer shelf, while the reverse pattern was observed in the imagery.
Temporal trends of computed first attenuation depth chlorophyll concentrations and CZCS estimates were in agreement on the coast (Figure 6). Both were typified by an increase through March, then a decrease until May. In May, CZCS estimates began to increase again while the computed concentrations continued to decrease. A depression in the computed concentrations near April 1 corresponded to a very weak wind event, and the peak near April 10 corresponded to the maximum wind event of spring 1979.

No such temporal trend was evident in CZCS chlorophyll estimates for the midshelf, while computed chlorophyll tended to increase throughout the spring (Figure 6). Again a peak corresponding to high wind and a valley corresponding to low wind was apparent.

On the outer shelf, little temporal variability was apparent in either the model or CZCS chlorophyll estimates (Figure 6 ). The two were in very good agreement, averaging about 0.93 and $0.79 \mathrm{mg}$ chlorophyll $\mathrm{m}^{-3}$, respectively for the same dates. However, computed chlorophyll concentrations on the slope region tended to somewhat exceed CZCS estimates on most days when images were available (Figure 6). A peak near April 1, during the weak wind period, was opposite the pattern on the coast and midshelf, as was a valley near April 10 for the high wind period.

\subsection{Phytoplankton Group Distributions}

As an initial condition of the model, we set netplankton and nanoplankton concentrations equal throughout the domain, at all depths. Results of the model were plotted as mean percent composition of total to investigate resultant distribution patterns (Figure 7). Netplankton dominated the total chlorophyll on the coast by 78 to $22 \%$ and nanoplankton on the slope by about the same ratio, 80 to $20 \%$. There was some oscillation in the regions between, but nanoplankton arrived at a fairly steady 63 to $37 \%$ dominance on the outer shelf by the end of the model run. At midshelf, nanoplankton initially dominated in early March, then netplankton attained dominance, reaching a maximum ratio of 64 to $36 \%$ on April 13 , before finally declining to 55 to $45 \%$ at the end of the run.

On the midshelf and outer shelf, patterns of dominance could be related to wind events. The initial slight domination of nanoplankton in early March on the midshelf corresponded to low wind speeds at the initiation of the model. Peak netplankton dominance on midshelf corresponded to the maximum wind event period of the model. The effect of this wind event can also be observed on the outer shelf, illustrated by a decline in nanoplankton dominance following their maximum percentage just after the low wind event of approximately April 1.

\subsection{Primary Production}

Estimates of primary production assumed a carbon to chlorophyll ratio of $50: 1$. Netplankton production dominated the total primary production on the coast and midshelf, while nanoplankton production dominated on the outer shelf and slope (Figure 8). These results conformed to the group distributions shown earlier. Primary production on the coast peaked early, reaching a maximum of $0.65 \mathrm{~g} \mathrm{C} \mathrm{m}^{-2}$ $\mathrm{d}^{-1}$ on April 1. Maxima on the other regions did not occur until late April to early May. The slope had the highest total primary production in the model domain, reaching a maxi- 


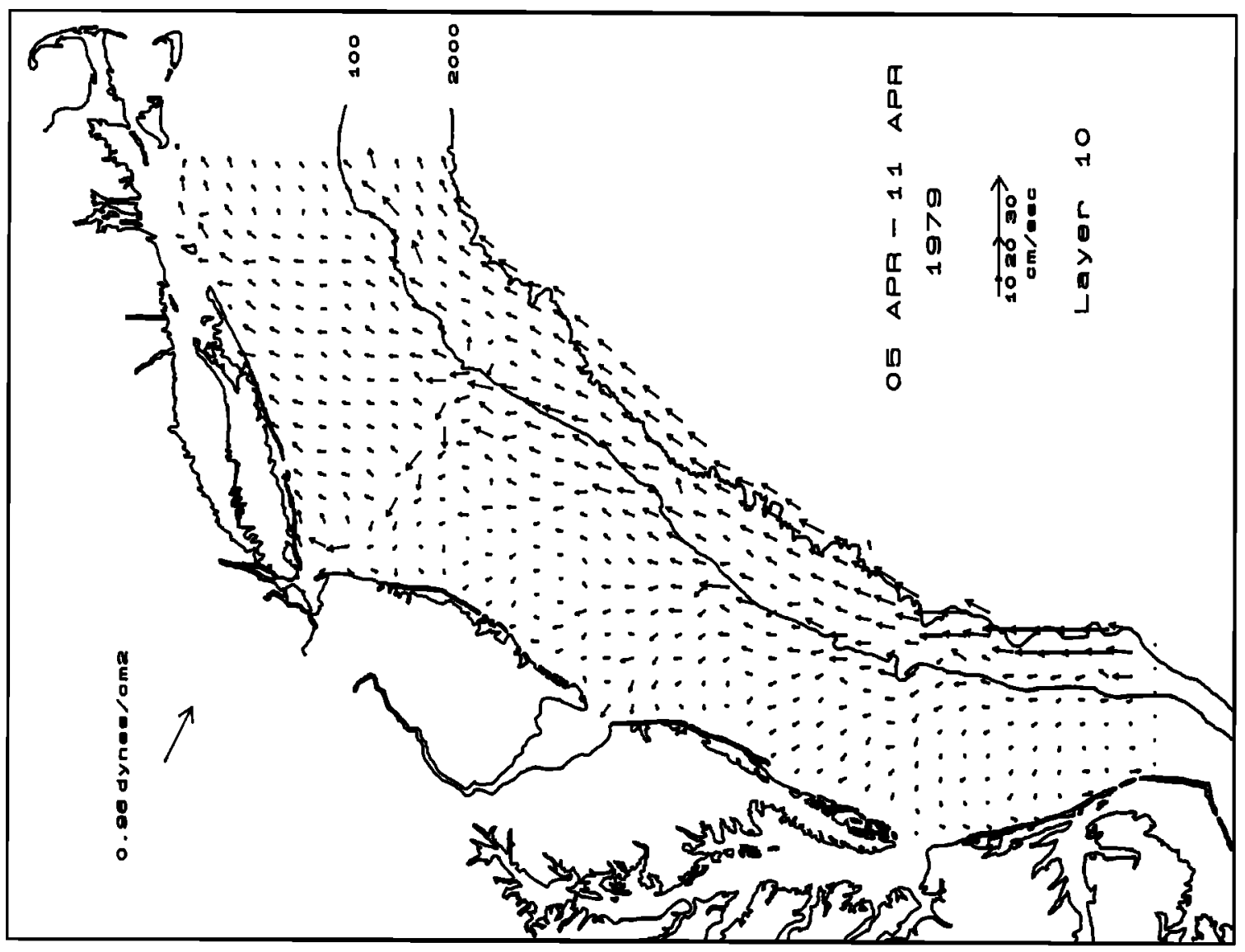

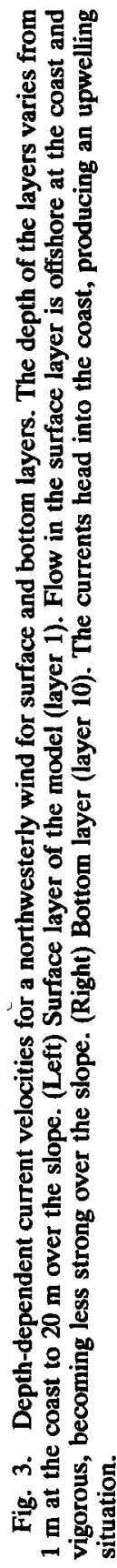

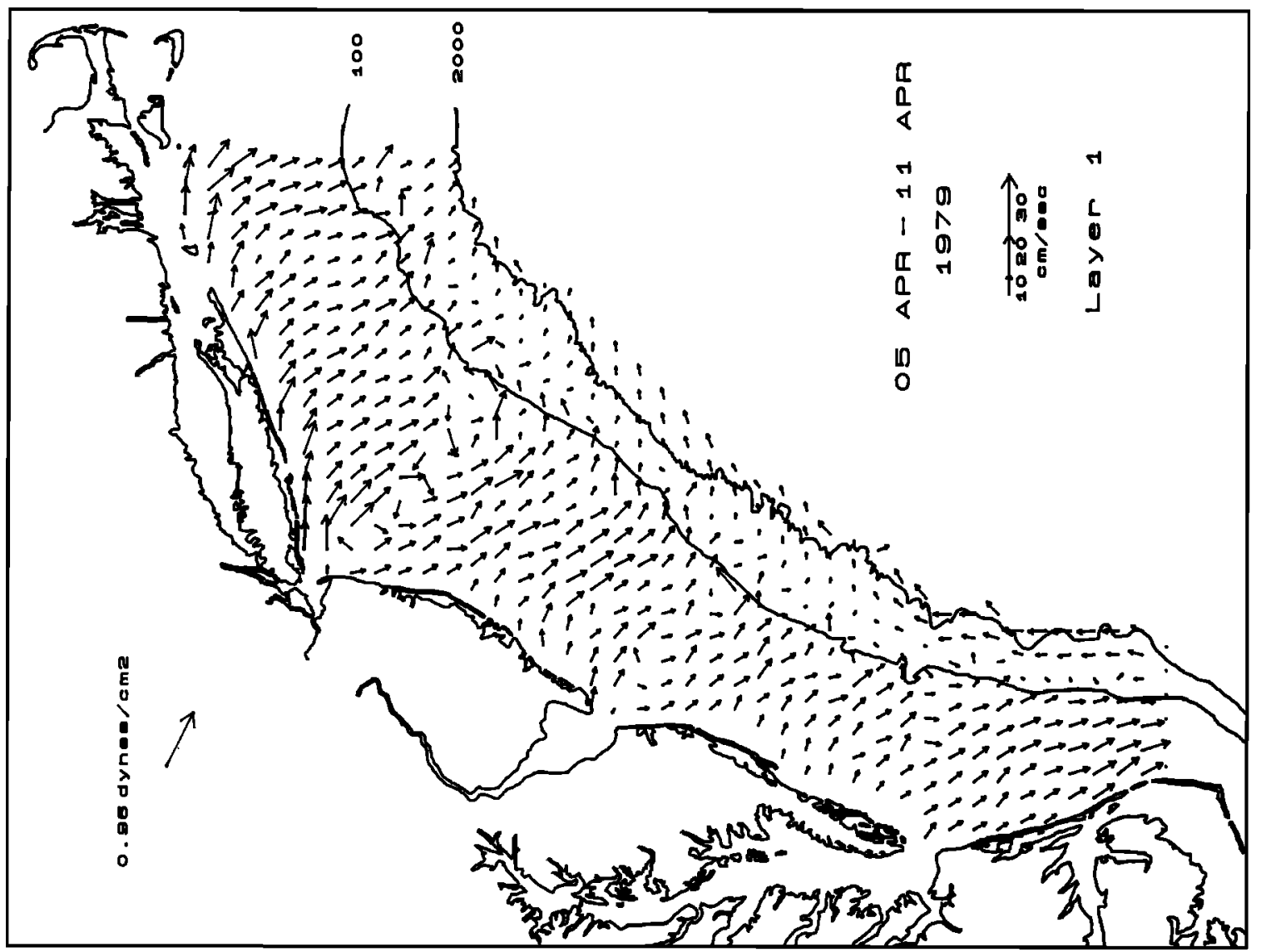



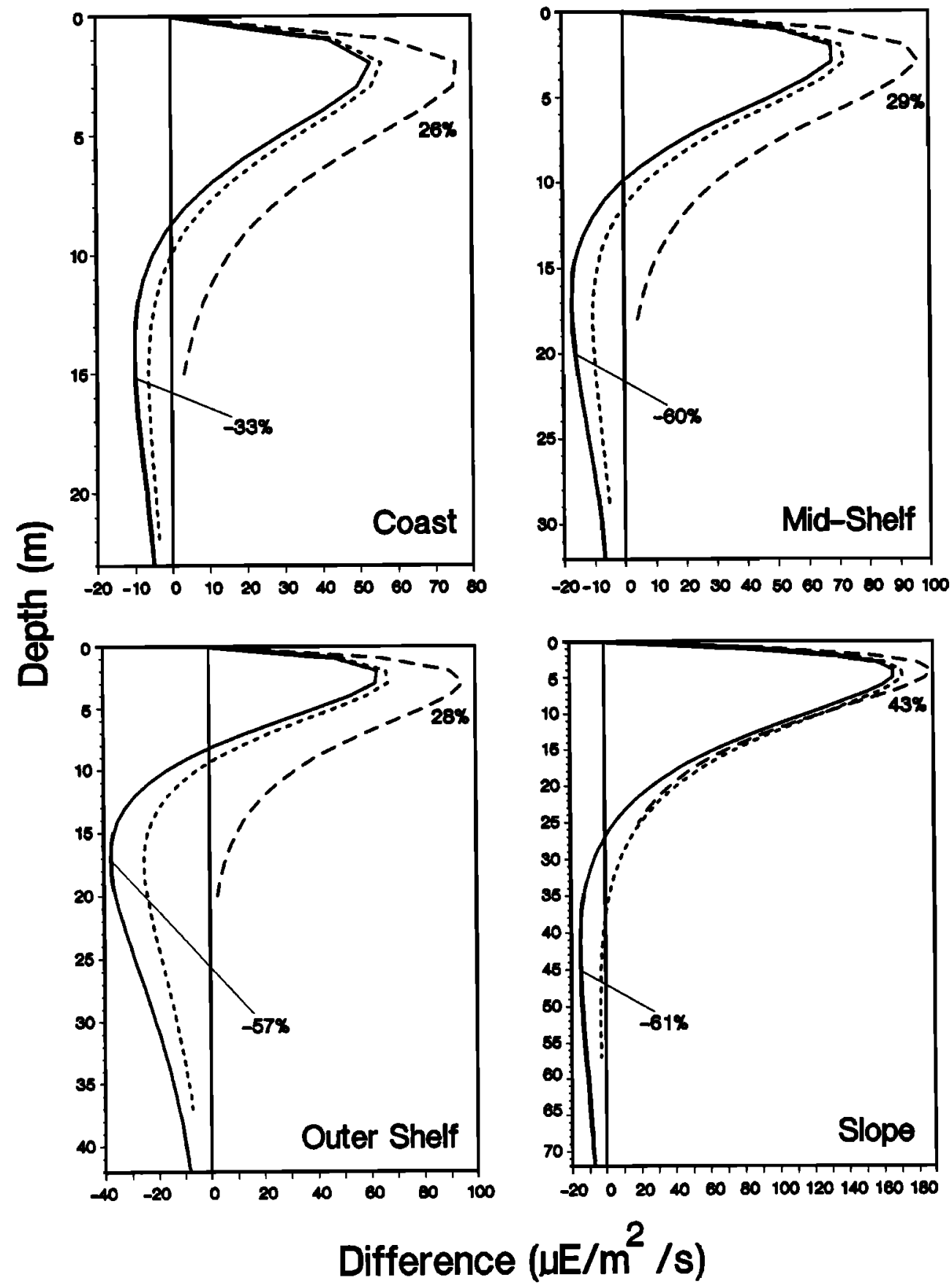

Fig. 4. Differences in total irradiance between the nonspectral and spectral attenuation models for a solar zenith angle of $40^{\circ}$. Positive difference indicates that the nonspectral model produces more irradiance than the spectral model; negative difference indicates the converse. Solid line: no chlorophyll; short-dashed line: low chlorophyll concentration $\left(0.5 \mathrm{mg} \mathrm{m}^{-3}\right)$; long-dashed line: high chlorophyll concentration $\left(5 \mathrm{mg} \mathrm{m}^{-3}\right)$. Data are shown only to the $1 \%$ light depth.

mum of $1.07 \mathrm{~g} \mathrm{C} \mathrm{m}^{-2} \mathrm{~d}^{-1}$ on May 1 . The midshelf region exhibited the second highest total production with a maximum of $0.73 \mathrm{~g} \mathrm{C} \mathrm{m}^{-2} \mathrm{~d}^{-1}$ on April 28. The outer shelf tended to have the lowest production, and did not reach its maximum of $0.51 \mathrm{~g} \mathrm{C} \mathrm{m}^{-2} \mathrm{~d}^{-1}$ until the end of the run, May 8 . The response of primary production to wind events was clearly apparent. The low wind event near April 1 corresponded to a sharp decline in total and nanoplankton primary production. The high wind event period near April 10 corresponded to a steep increase in total and netplankton primary production on the midshelf and a sharp decline in total and nanoplankton primary production on the slope. Only a modest increase in production was observed on the coast during this period.

Computed primary production values for the coast compared very favorably with in situ measurements both for 1979 and from long-term studies (Table 2). Computed values at midshelf were somewhat lower than those measured in March, but within reasonable agreement in April. The model substantially underestimated production on the outer shelf, but computed values on the slope were within a wide range of reported values for 1979 and 1984 . 


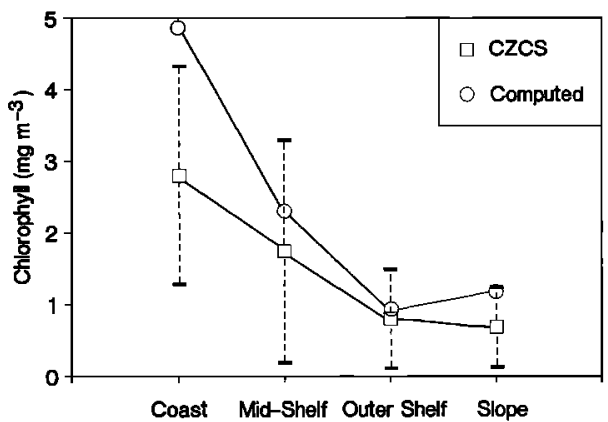

Fig. 5. Comparison of computed first attenuation depth chlorophyll concentrations and CZCS-estimated chlorophyll as means within regions for spring 1979. Standard deviations of CZCSestimated chlorophyll are shown along with the means.

\subsection{Vertical Time Series}

A transect extending seaward from just north of the Chesapeake Bay was selected to illustrate the vertical distributions of chlorophyll, and to view the interrelations between vertical physical processes and biological processes from coast to slope. The transect contained bathymetric variability typical of the MAB and was far enough away from the mouth of the Chesapeake Bay to avoid undue influence.

Depth-independent chlorophyll distributions on February 28 (Plate 1) were a consequence of the initial conditions. Low winds and mixing (mean vector wind stress, 0.09 dyn $\mathrm{cm}^{-2} ; A_{z}=14.8 \mathrm{~cm}^{2} \mathrm{~s}^{-1}$ at the center latitude of the grid) of the subsequent period resulted in larger biomasses near the bottom on the shelf by March 4 . Bottom chlorophyll increased from a mean of $\approx 2.1$ to $4.1 \mathrm{mg} \mathrm{m}^{-3}$ on the coast (Plate 1). Similar factor-of-2 increases occurred on the other

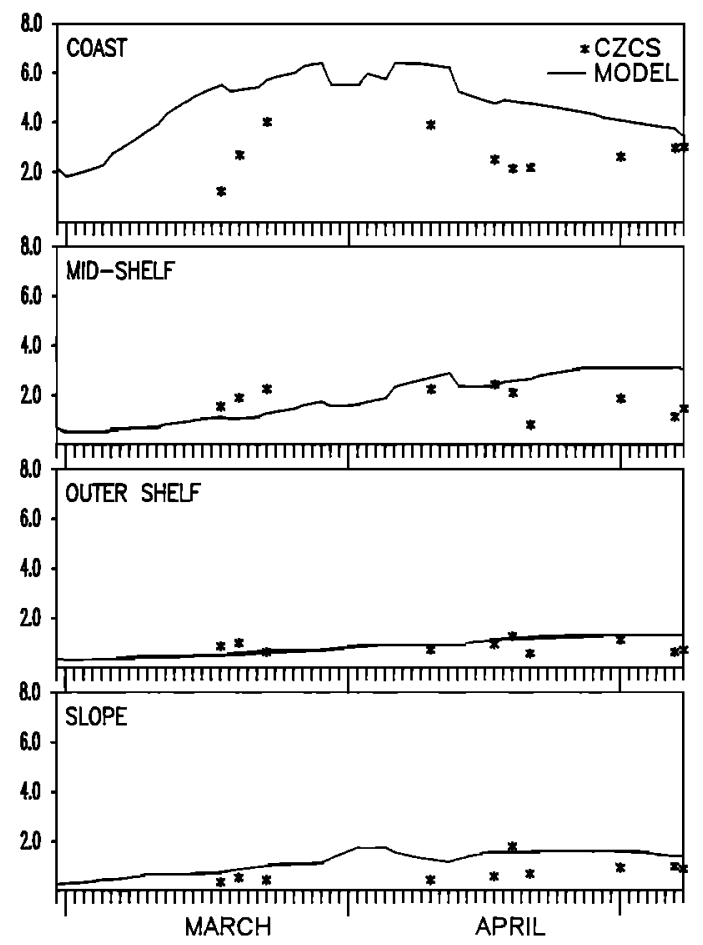

Fig. 6. Temporal comparison of computed first attenuation depth chlorophyll concentrations with CZCS estimates of chlorophyll (in $\mathrm{mg}$ chlorophyll $\mathrm{m}^{-3}$ ) as means within regions.

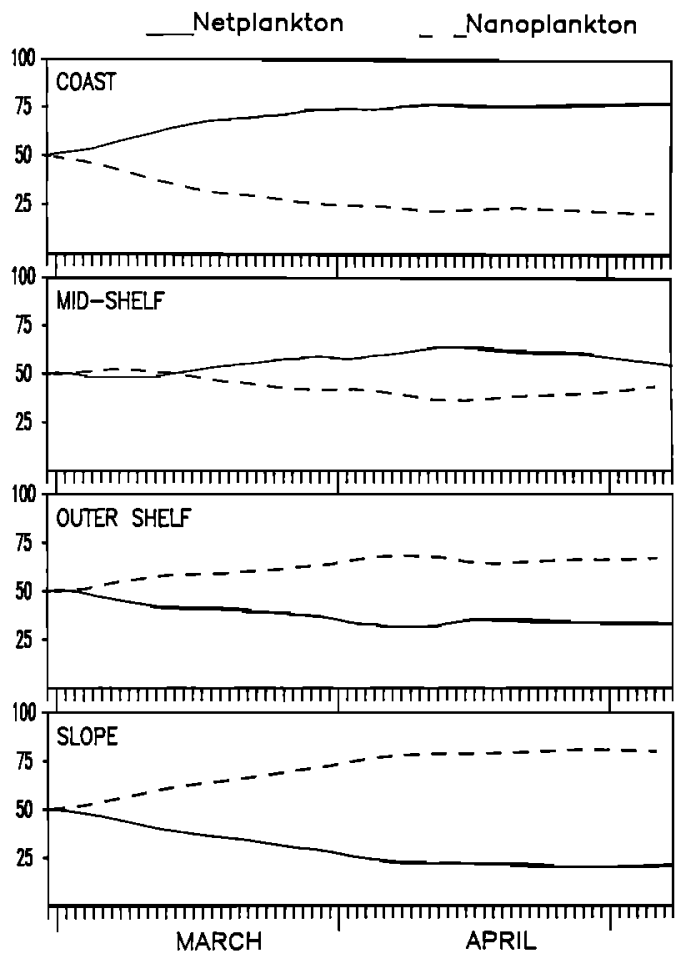

Fig. 7. Computed relative abundance (in percent of total) of netplankton and nanoplankton as means within regions.

regions, except the slope where bottom layer concentrations decreased by about the same factor.

The next two periods, March 5-17, were characterized by higher mixing and increases in phytoplankton abundance.

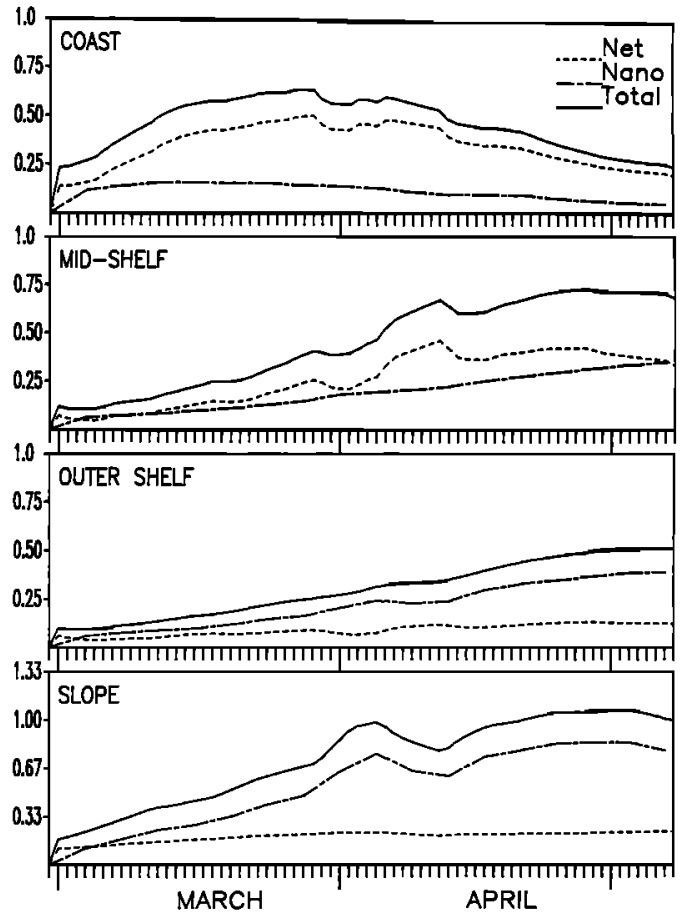

Fig. 8. Computed primary production (units $\mathrm{g} \mathrm{C} \mathrm{m}^{-2} \mathrm{~d}^{-1}$ ) expressed as total, netplankton, and nanoplankton fractions and plotted as means within regions. Production assumed a carbon to chlorophyll ratio of $50: 1$. 
TABLE 2. Comparison of Computed Primary Production Within Regions With Observations in the MAB

\begin{tabular}{ccll}
\hline & $\begin{array}{c}\text { Primary } \\
\text { Produc- } \\
\text { tion, g } \\
\mathrm{C} \mathrm{m}^{-2}\end{array}$ & & \\
& $\mathrm{~d}^{-1}$ & \multicolumn{1}{c}{ Time } & \multicolumn{1}{c}{ Reference } \\
\hline Coast & 0.63 & March 1979 & von Bock [1983a] \\
& 0.59 & March 1977-1980 & Walsh et al. [1987] \\
Midshelf & 0.59 & March 1979 & present model \\
& 0.79 & March 1979 & von Bock [1983a] \\
& 0.66 & March 1977-1980 & Walsh et al. [1987] \\
& 0.28 & March 1979 & present model \\
& 0.41 & April 1977-1980 & Walsh et al. [1987] \\
Outer & 0.61 & April 1979 & present model \\
shelf & 1.15 & March 1979 & von Bock [1983a] \\
& 0.55 & March 1977-1980 & Walsh et al. [1987] \\
& 0.60 & March 1984 & Falkowski et al. [1988] \\
& 0.52 & March 1984 & Smith and Lane [1988] \\
Slope & 0.20 & March 1979 & present model \\
& 2.03 & March 1979 & von Bock [1983a] \\
& 0.50 & March 1984 & Falkowski et al. [1988] \\
& 0.55 & March 1979 & present model \\
& 1.88 & April 1984 & Falkowski et al. [1988] \\
& 0.96 & April 1984 & Smith and Lane [1988] \\
& 0.95 & April 1979 & present model \\
\hline
\end{tabular}

Chlorophyll mean abundance on the coast and midshelf increased from 1.9 and $0.5 \mathrm{mg} \mathrm{m}^{-3}$, respectively, to 3.4 and $0.7 \mathrm{mg} \mathrm{m}^{-3}$. Bottom accumulations exceeded $10 \mathrm{mg} \mathrm{m}^{-3}$ on the coast and were even greater $\left(>15 \mathrm{mg} \mathrm{m}^{-3}\right)$ at the mouths of the three estuaries. Strong offshore surface layer current velocities and onshore bottom velocities from March 11 to March 17 produced an upwelling coastal circulation with a maximum of $8 \mathrm{~m} \mathrm{~d}^{-1}$. This condition resulted in an increase in phytoplankton abundance in the coastal and midshelf regions (mean surface biomass, 4.7 and $1.1 \mathrm{mg} \mathrm{m}^{-3}$, respectively).

In the following two periods, March 18-28, there was moderate mixing and upwelling (maximum $9 \mathrm{~m} \mathrm{~d}^{-1}$ ) from a northwest wind event $\left(0.77\right.$ dyn $\mathrm{cm}^{-2}$ vector stress, $A_{z}=$ $47.1 \mathrm{~cm}^{2} \mathrm{~s}^{-1}$ ). Meanwhile the slope bloom intensified and deepened (Plate 1). High bottom chlorophyll concentrations on the coast (mean, $\approx 8.7 \mathrm{mg} \mathrm{m}^{-3}$ ) conformed to observations from the R/V Albatross IV [von Bock, 1983a] for the same period (Figure 9) for which a mean of $8.7 \mathrm{mg} \mathrm{m}^{-3}$ was observed. Observed vertical trends of chlorophyll on the midshelf and outer shelf were highly variable, as were magnitudes, but the mean values more or less suggested vertical homogeneity, supporting computed trends on March 21 . The observed vertically homogeneous chlorophyll profile on the slope was also in agreement with the computed profile. In general, however, computed surface chlorophyll appeared to be low relative to observed chlorophyll seaward of the coast at this time.

Surface nitrate data from the R/V Albatross $I V$ during this time in 1979 [von Bock, 1983a] were in reasonable agreement with computed concentrations on the coast, outer shelf, and slope, but the model tended to overestimate observed surface $\mathrm{NO}_{3}$ on the midshelf (Figure 10). Vertically homogeneous profiles of observed coast $\mathrm{NO}_{3}$ also matched those computed, but there were high bottom concentrations of observed $\mathrm{NO}_{3}$ on the midshelf and outer shelf not apparent in the model. Some observed depth profiles matched the vertically uniform profiles of the model, however. Computed slope $\mathrm{NO}_{3}$ showed a slight depth trend, increasing from $5.5 \mu \mathrm{g}$ at. $\mathrm{L}^{-1}$ at the surface to $\approx 6.5 \mu \mathrm{g}$ at. $\mathrm{L}^{-1}$ at the slope pycnocline. This trend qualitatively agreed with the model but contrasted in magnitude: Observed $\mathrm{NO}_{3}$ increased from $\approx 6 \mu \mathrm{g}$ at. $\mathrm{L}^{-1}$ at the surface to $\approx 17 \mu \mathrm{g}$ at. $\mathrm{L}^{-1}$ at $200 \mathrm{~m}$. Ammonium data suggested that computed bottom $\mathrm{NH}_{4}$ concentrations were reasonable, as was the vertical homogeneity of the mean depth profiles in all regions (Figure 11).

The next wind period, March 29 to April 1, was characterized by low mean vector wind stress $\left(0.25 \mathrm{dyn} \mathrm{cm}^{-2}\right.$ from the south) and low mixing $\left(A_{z}=17.7 \mathrm{~cm}^{2} \mathrm{~s}^{-1}\right)$. The result of this period was depletion of chlorophyll from the surface layer on the shelf, accumulation on the bottom, and a large bloom of phytoplankton in the surface layer on the slope, $>1.5 \mathrm{mg} \mathrm{m}^{-3}$ (Plate 2).

The following period, April 5-11, was the strongest wind event of spring 1979. A storm from the northwest had mean vector wind stress of $0.96 \mathrm{dyn}^{-2}$ and created massive turbulence and mixing $\left(A_{z}=69.5 \mathrm{~cm}^{2} \mathrm{~s}^{-1}\right)$. Strong offshore current velocities in the surface layer and strong onshore bottom flow in the bottom created an upwelling circulation on the coast of maximum $9 \mathrm{~m} \mathrm{~d}^{-1}$. In response to this wind event, surface layer chlorophyll increased on the shelf (Plate 2). Areas of high surface chlorophyll extended seaward, and bottom layer chlorophyll decreased from $>10$ to $<9 \mathrm{mg} \mathrm{m}^{-3}$. In contrast, the slope chlorophyll bloom nearly disappeared.

A CZCS image was available for the previous day, April 10, 1979, and showed general agreement with computed chlorophyll distribution patterns for the first attenuation depth (Plate 3). High chlorophyll extended to the 60-m isobath off the coast of New Jersey and low chlorophyll was apparent in the Hudson Shelf Valley, located offshore of the mouth of the Hudson River. Indentations in the midshelf chlorophyll distributions were apparent in the imagery at the 60- $\mathrm{m}$ isobath between the Hudson River and Delaware Bay east-southeast of Delaware Bay, and were almost identically matched by the model, as was an extension of $>1.5 \mathrm{mg} \mathrm{m}^{-3}$ concentrations just south of the Delaware Bay indentation. A plume emanating south from the Chesapeake Bay in the image was also well represented in the model. The Delaware Bay plume in the image was not apparent in the model, owing to the overall overestimation of the model relative to the CZCS in the coast region (computed first attenuation depth, $6.4 \mathrm{mg} \mathrm{m}^{-3}$; CZCS mean, $4.0 \mathrm{mg} \mathrm{m}^{-3}$ ). The model matched the CZCS in magnitude of chlorophyll concentrations on the midshelf (mean difference, $0.5 \mathrm{mg} \mathrm{m}^{-3}$ ) and the outer shelf (mean difference, $0.2 \mathrm{mg} \mathrm{m}^{-3}$ ), but overestimated slope chlorophyll by a factor of $3\left(1.2\right.$ to $\left.0.4 \mathrm{mg} \mathrm{m}^{-3}\right)$. However, $90 \%$ of the CZCS image over the slope was obscured by clouds.

Winds shifted to the northeast and decreased to 0.23 dyn $\mathrm{cm}^{-2}$ in the following period, April 12-16, and mixing decreased $\left(A_{z}=23.3 \mathrm{~cm}^{2} \mathrm{~s}^{-1}\right)$. As a result, chlorophyll concentrations decreased in the surface layer and increased in the bottom layer on the shelf (Plate 2). Maximum bottom concentrations occurred farther seaward than before the wind event of April 5-11, now lying at midshelf, as opposed to against the coast in the preceding period. Slope chlorophyll regained its former $>1.5 \mathrm{mg} \mathrm{m}^{-3}$ level. Low winds/ mixing continued until the end of the model run and produced cross-shore chlorophyll patterns that did not change 

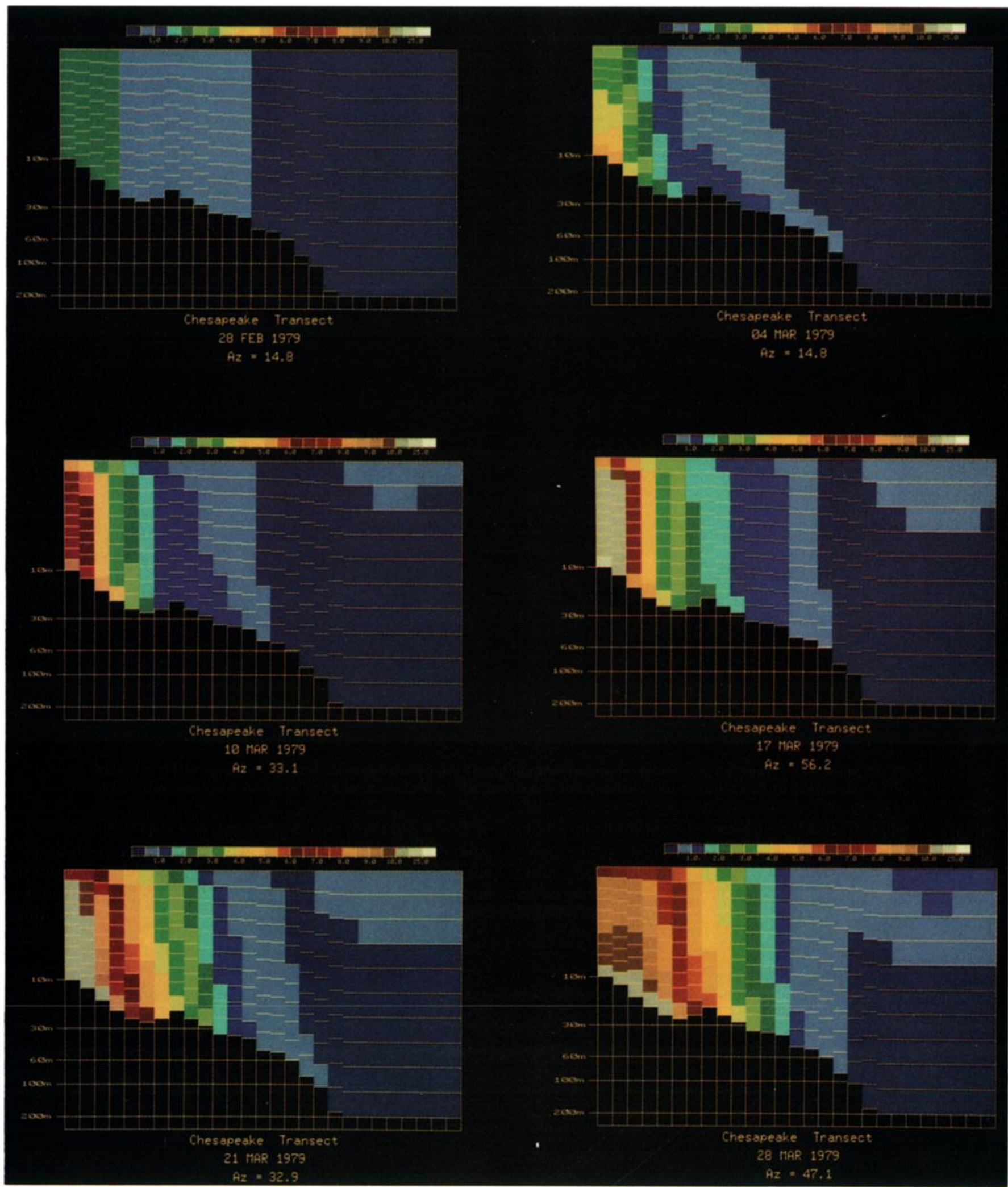

Plate 1. Time series of vertical chlorophyll profiles (in millıgrams per cubic meter) for a transect extending seaward from the coast just north of the Chesapeake Bay. Depicted is a time series from February 28 to March 28, 1979.

substantially. What was apparent during this time was continued depletion of coastal chlorophyll biomass at all depths, leading to the appearance of a midshelf maximum near the 30-m isobath by April 27. Chlorophyll biomass decreased on the coast but increased at midshelf. Bottom layer chloro- phyll concentrations decreased on the shelf (Plate 2). On the slope, surface layer chlorophyll continued to increase, as did outer shelf concentrations generally. In the bottom layer, chlorophyll values decreased on the coast, but values increased somewhat at midshelf. On the slope, bottom layer 


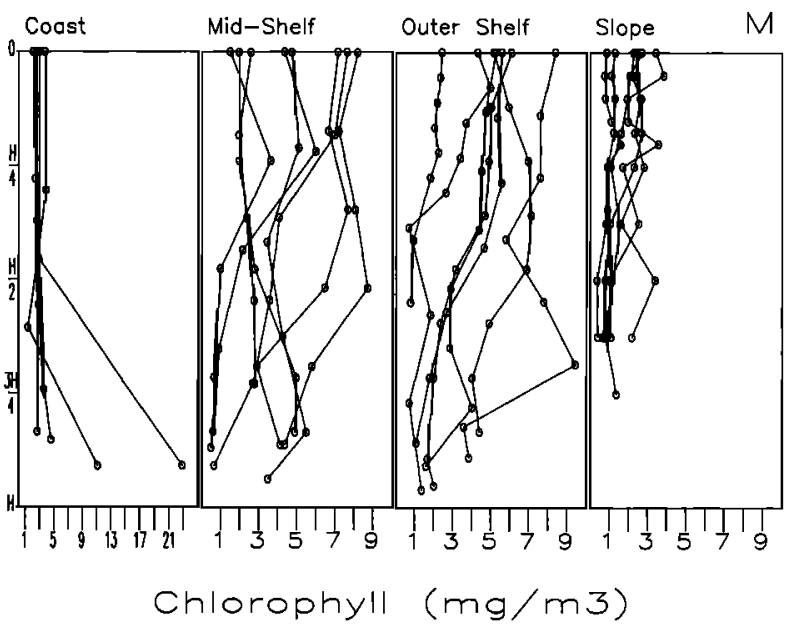

Fig. 9. Observed depth profiles of chlorophyll from the R/V Albatross IV for March 15-24, 1979, divided into regions.

chlorophyll was reduced to zero at the southern and eastern portion of the slope.

Computed vertical trends of chlorophyll decreasing with depth on the slope, and increasing with depth on the midshelf agreed with those observed by the $\mathrm{R} / \mathrm{V}$ Advance II [von Bock, 1983b] for late April/early May (Figure 12). Observed
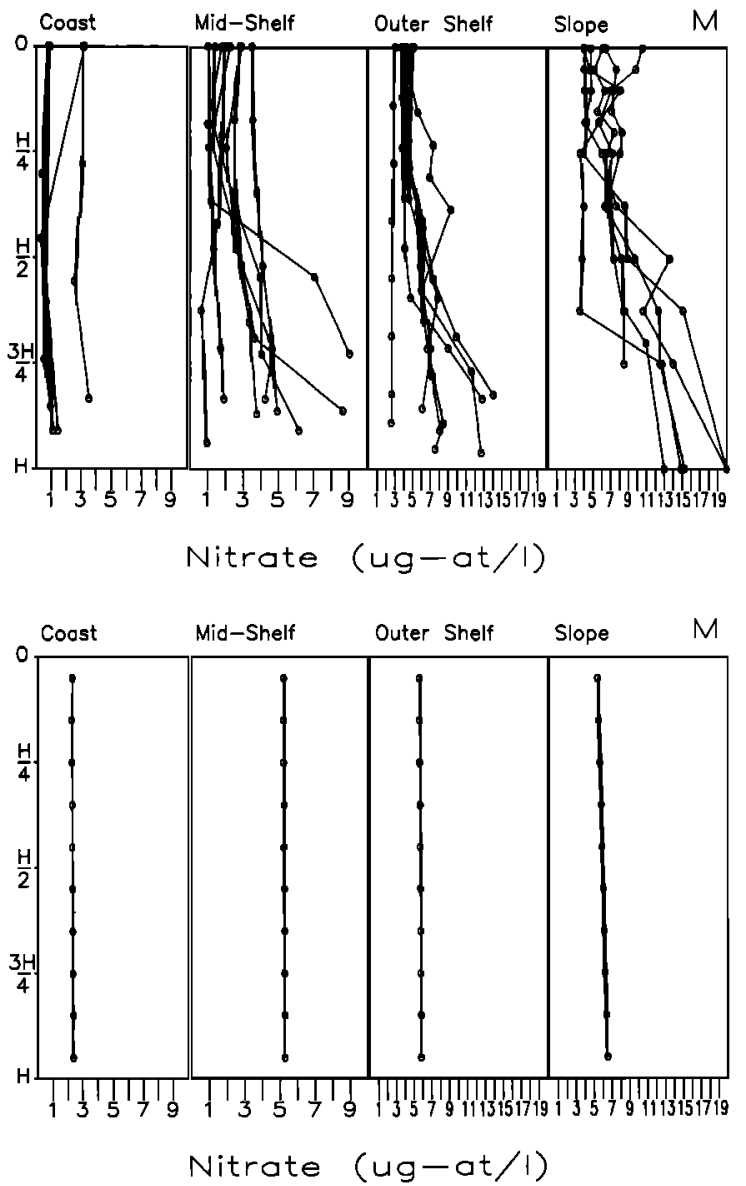

Fig. 10. (Top) Observed depth profiles of nitrate from the R/V Albatross IV for March 15-24, 1979, divided into regions. (Bottom) The mean of computed depth profiles of nitrate within each region.
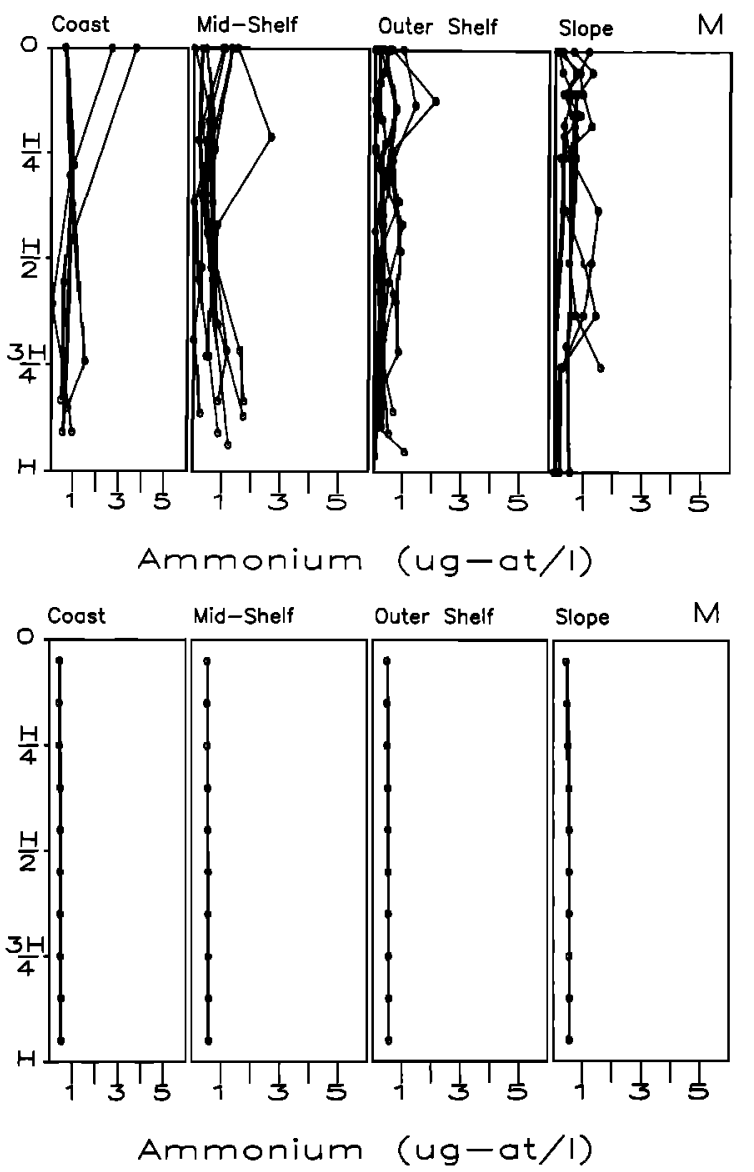

Fig. 11. (Top) Observed depth profiles of ammonium from the $\mathrm{R} / \mathrm{V}$ Albatross $I V$ for March 15-24, 1979, divided into regions. (Bottom) The mean of computed depth profiles of ammonium within each region.

outer shelf vertical trends were highly variable. At times they suggested a decrease in concentration with depth, at other times a subsurface maximum, occasionally an increase with depth, and sometimes near-vertical homogeneity. Computed trends on the outer shelf on the Chesapeake transect conformed only to the latter. Although the computed vertical trends of chlorophyll were well supported by observations, computed surface biomasses appeared to underestimate the observed values on the slope and exceed those on the midshelf. Computed outer shelf surface chlorophyll again underestimated the observed value, as in March, but the underestimation was less.

Exhaustion of $\mathrm{NO}_{3}$ on the coast in the model was supported by nitrate data from the R/V Advance II [von Bock, $1983 b$ ] for the same period in 1979 (Figure 13). Computed surface concentrations of $\mathrm{NO}_{3}$ were also reasonable as compared to observations on the midshelf, outer shelf, and slope, although slightly higher than observed. Observed vertical distributions of $\mathrm{NO}_{3}$ were variable on the midshelf and outer shelf. Although some profiles agreed with the vertically homogeneous computed profiles, most suggested a benthic source, as evidenced by the observed high bottom concentrations. As in March, computed slope $\mathrm{NO}_{3}$ increased from $\approx 4.3 \mu \mathrm{g}$ at. $\mathrm{L}^{-1}$ at the surface to $\approx 6.0 \mu \mathrm{g}$ at. $\mathrm{L}^{-1}$ near the bottom. This trend conformed to observations except in magnitude near the pycnocline, where the ob- 

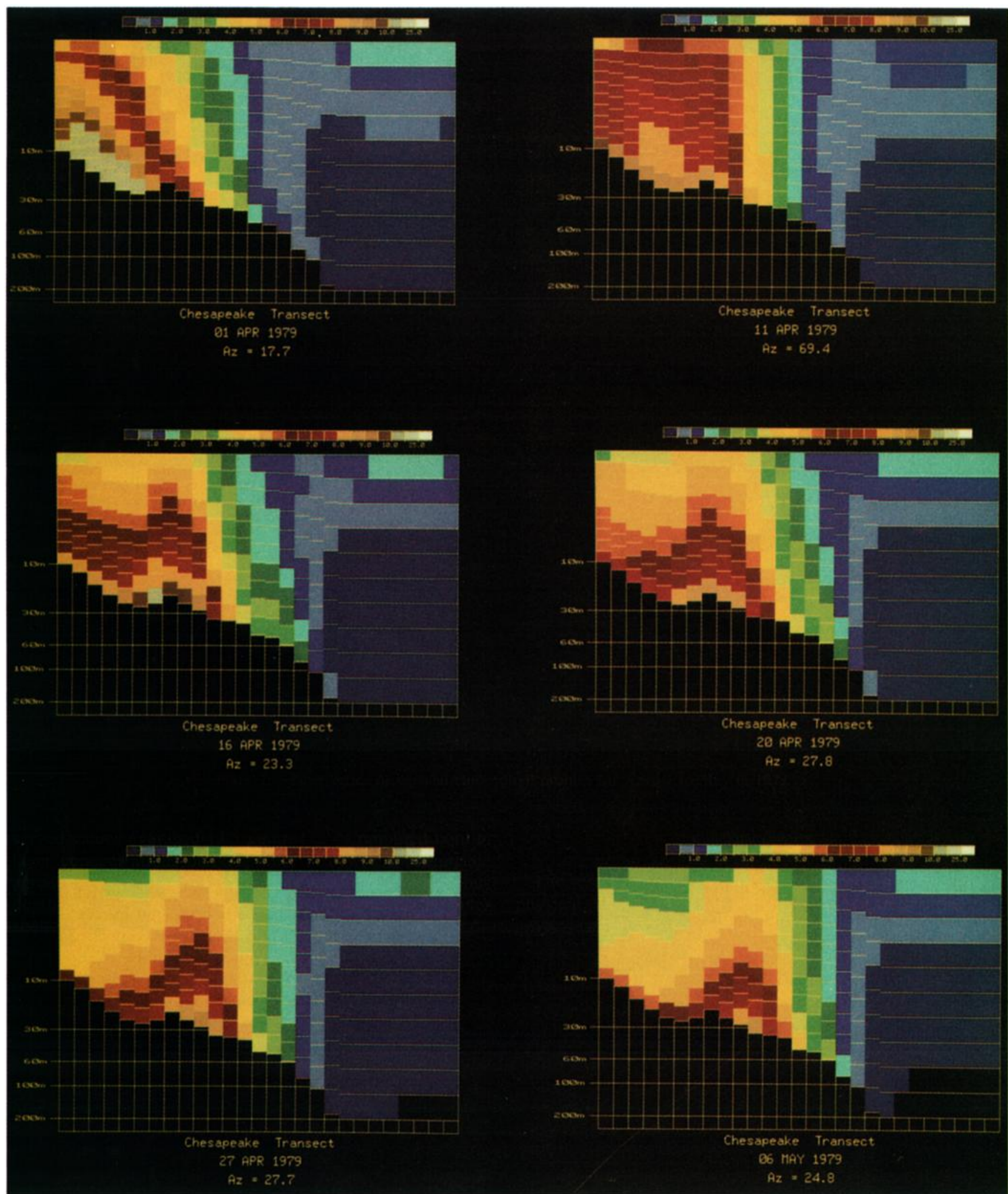

Plate 2. Time series of vertical chlorophyll profiles for April 1 to May 6, 1979.

served values averaged $13.5 \mu \mathrm{g}$ at. $\mathrm{L}^{-1}$. Computed bottom layer concentrations of $\mathrm{NH}_{4}$ were also within reasonable agreement with observed values, as were the homogeneous depth profiles except on the coast and perhaps on the outer shelf, which showed very high variability (Figure 14).

\section{Discussion}

The results suggest that a model incorporating first-order physical, biological, and optical principles can describe the gross features of phytoplankton dynamics in the MAB. 


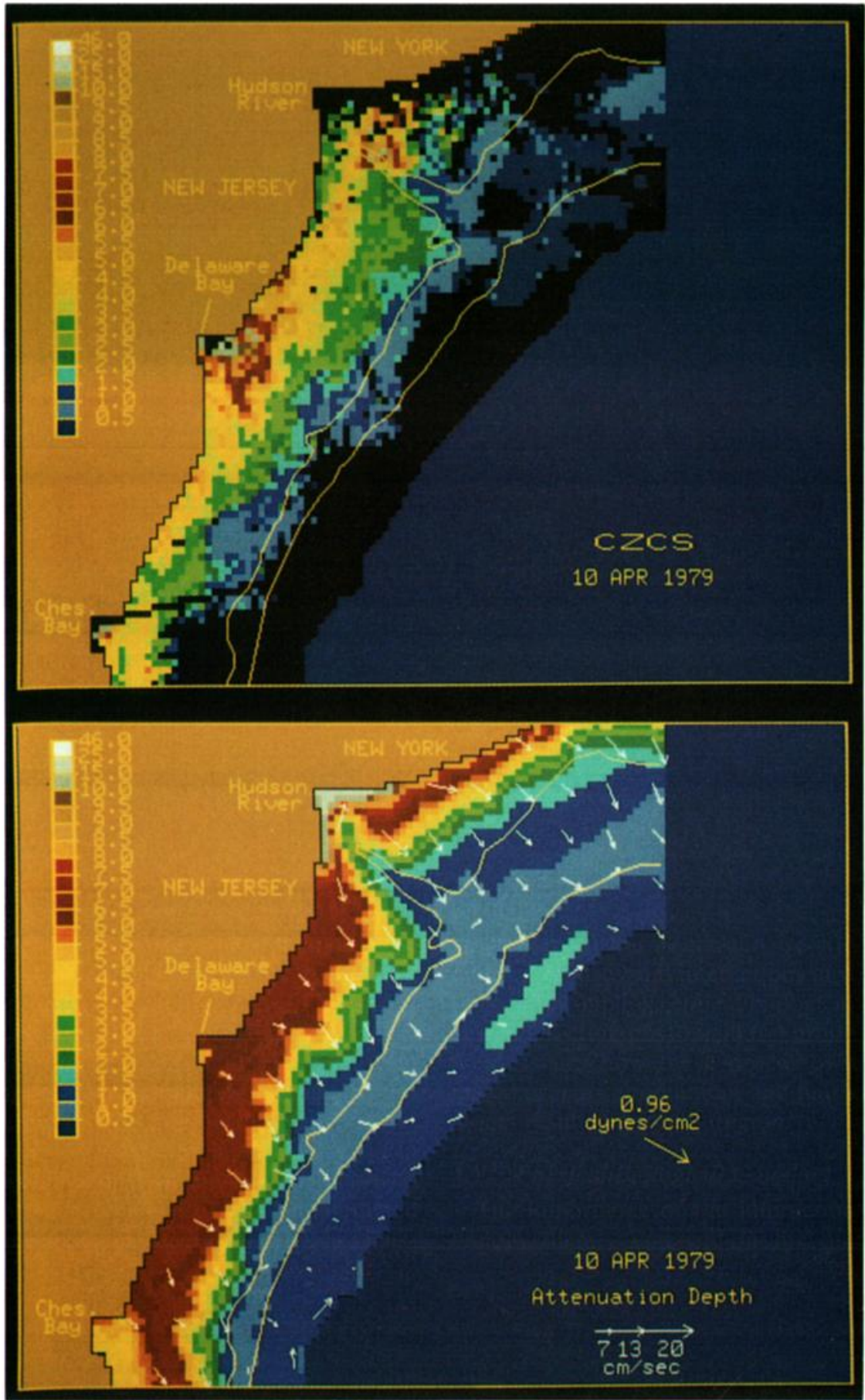

Plate 3. Comparison of horizontal distributions of computed chlorophyll concentrations for the first attenuation depth with CZCS imagery for April 10, 1979. White arrows depict surface layer (layer 1) current velocities; the yellow arrow depicts the surface stress direction (magnitude is denoted).

Comparison of computed first attenuation depth chlorophyll with CZCS estimates was very good (within I standard deviation, except on the coast), when expressed as means within the four major regions of the MAB (Figure 5).

Phytoplankton distributions computed by the model were determined by a complex interplay among mixing, advection, growth as a function of light and nutrient availability, and ingestion. The processes interacted in different ways in each of the four major regions of the MAB, and with different relative importance. The processes also interacted in different ways depending upon the dominant phytoplank- ton group. In the discussion we will describe some of the major processes and interactions at work: namely, physical/ biological coupling, optical/biological coupling, and the processes affecting phytoplankton group distributions. We will then discuss how these processes and interactions determined primary production, and finish with a synopsis of the model results region by region.

\subsection{PhysicallBiological Coupling}

The importance of the interaction between physics and biology clearly emerged in the model results. Estuarine 


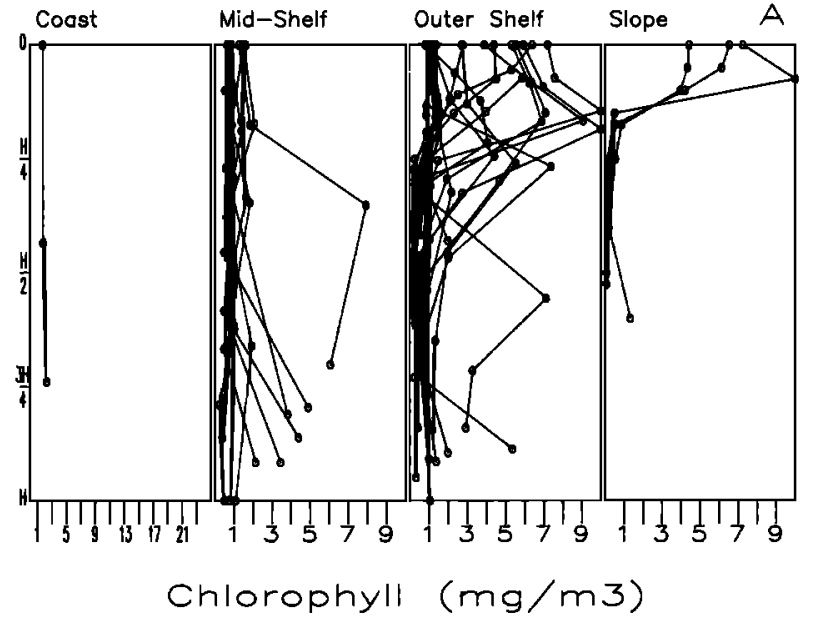

Fig. 12. Observed depth profiles of chlorophyll from the $R / V$ Advance II for April 27 to May 2, 1979, divided into regions.

influx as well as vertical advection, mixing, and horizontal advection events were critical in determining the horizontal and vertical patterns of the biological and chemical constituents of the model. The overall favorable comparison of computed first attenuation depth chlorophyll concentrations
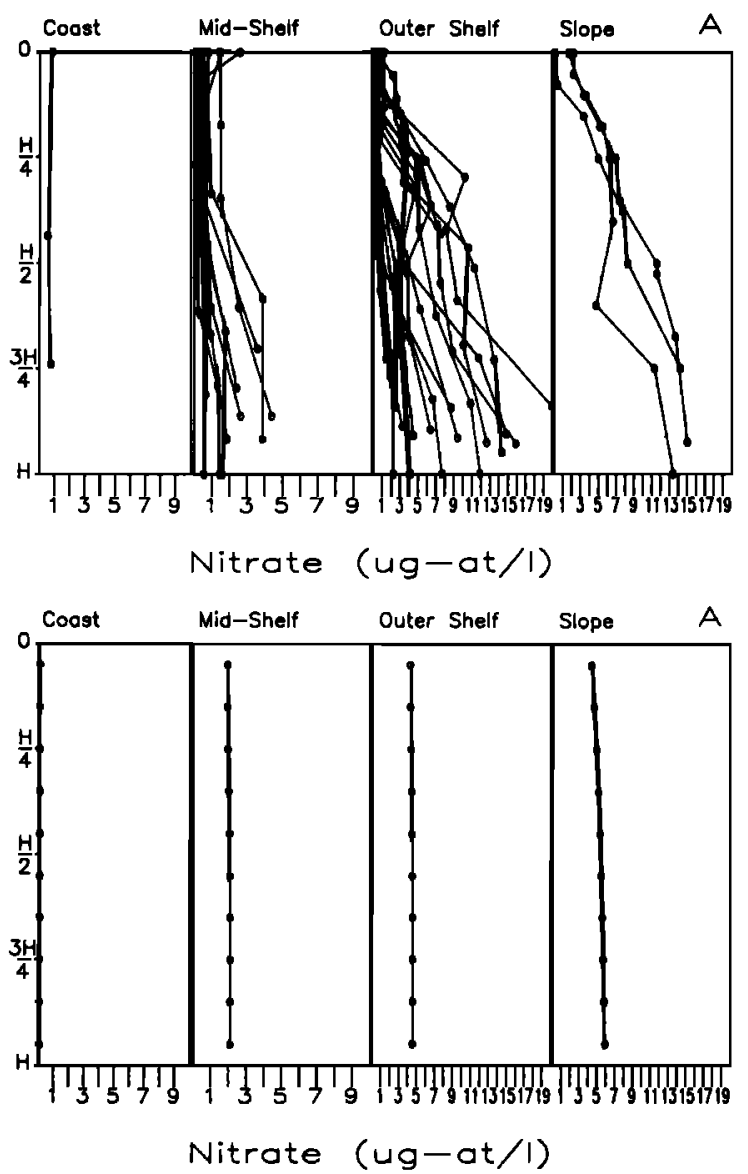

Fig. 13. (Top) Observed depth profiles of nitrate from the $R / V$ Advance II for April 27 to May 2, 1979, divided into regions. (Bottom) The mean of computed depth profiles of nitrate within each region.
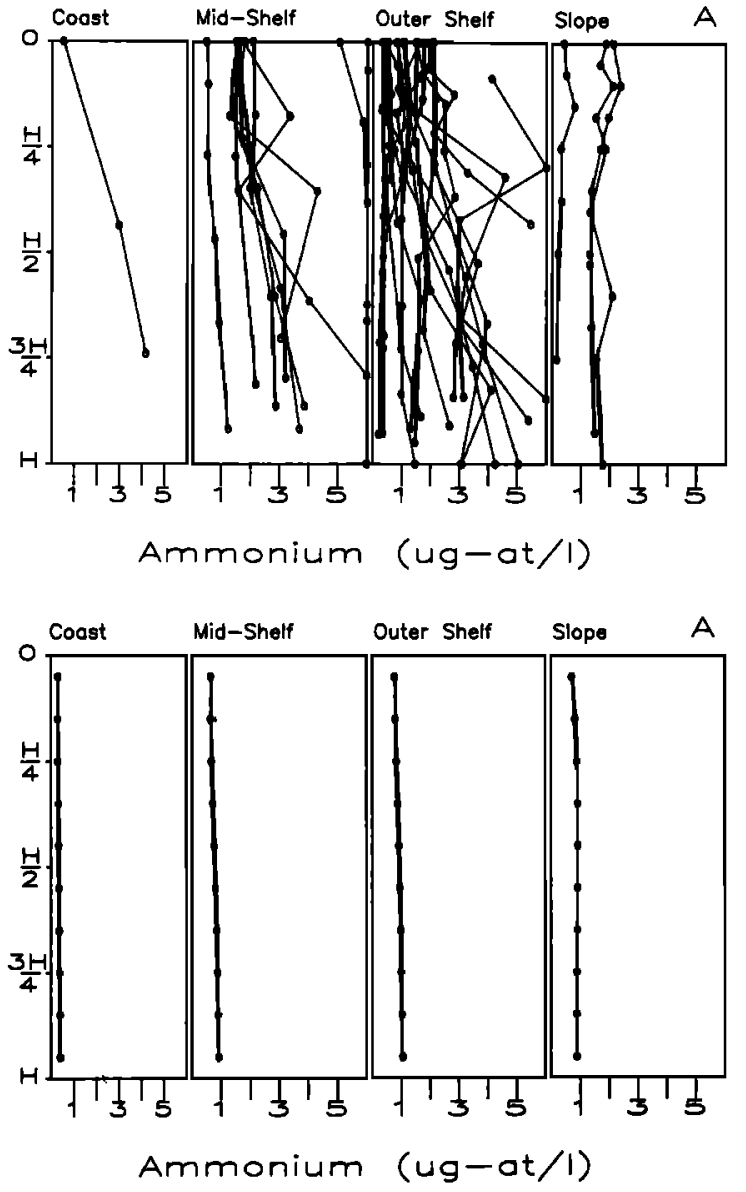

Fig. 14. (Top) Observed depth profiles of ammonium from the R/V Advance II for April 27 to May 2, 1979, divided into regions. (Bottom) The mean of computed depth profiles of ammonium within each region.

with CZCS imagery (Plate 3) and with respect to large-scale (regional) horizontal distributions (Figures 5 and 6) suggested that this coupling was realistically represented in the model. However, a more detailed discussion with reference to the vertical time series (Plates 1 and 2) aids in bringing the mechanisms of the coupling to light.

Shortly after initialization of the model, sinking netplankton produced a transfer of biomass from surface to bottom layers on the shelf, resulting in a doubling of bottom layer concentrations (Plate 1). On the slope, netplankton sank through the 200-m pycnocline and were lost to the model domain. Thus bottom layer concentrations on the slope decreased by about a factor of 2 .

Higher mixing in the next two periods suspended shelf phytoplankton within the high light environment of the euphotic zone and enabled growth, as evidenced by the increase in primary production (see Figure 8). Despite this growth, netplankton continued sinking to the bottom layer during this period, resulting in accumulations exceeding 10 $\mathrm{mg} \mathrm{m}^{-3}$ on the coast. The higher temperatures of the slope enabled phytoplankton to attain even higher growth rates than inshore and thus compensate losses by downward mixing to remain abundant in the surface layers.

Low winds/mixing for the wind period March 29 to April 1 resulted in the depletion of chlorophyll from the surface layer on the shelf and accumulation on the bottom via 
sinking netplankton. In contrast, a large bloom of predominantly nanoplankton occurred in the surface layer on the slope (Plate 2). The lower winds/mixing of this period reduced downward mixing and enabled the more buoyant nanoplankton to remain in the euphotic zone and grow.

The northwesterly storm in the period April 5-11 had dramatic effects on chlorophyll distributions. Due to vigorous upwelling and mixing, netplankton were resuspended on the shelf, resulting in high primary production (see Figure 8). Vertical distributions became more uniform as bottom concentrations decreased. Offshore advection extended areas of high surface chlorophyll seaward. In contrast, the slope chlorophyll bloom nearly disappeared as a result of downward mixing of nanoplankton. Depth-averaged flow was up the Hudson Shelf Valley (toward the mouth of the Hudson River) making the canyon clearly apparent in chlorophyll distributions as a region of low chlorophyll (see Plate 3 ).

When winds shifted to the northeast and decreased in the next period, April 12-16, phytoplankton (especially netplankton) sank out of the surface layer into the bottom layer on the shelf (Plate 2). Maximum bottom concentrations now occurred at midshelf instead of the coast. This was the result of resuspension, growth, and offshore advection in the surface layers in the previous period, and subsequent deposition of sinking netplankton in the present. Slope chlorophyll concentrations increased due to the reduced mixing.

Subsequent periods were characterized by relatively low winds/mixing. Nitrate exhaustion on the coast prevented substantial primary production (see Figure 8) such that coast phytoplankton were growing almost exclusively on regenerated $\mathrm{NH}_{4}$ except at estuaries where a source existed. Thus chlorophyll biomass decreased on the coast but increased at midshelf due to available $\mathrm{NO}_{3}$ and the beginning of replacement of netplankton by nanopiankton (see Figure 7 ). This led to the appearance of a midshelf maximum near the $30-\mathrm{m}$ isobath by April 27. Bottom layer chlorophyll concentrations decreased on the coast (Plate 2) due to benthic ingestion and the lack of recruitment from above by sinking netplankton. However, bottom concentrations increased somewhat at midshelf due to sinking netplankton. Outer shelf concentrations generally increased as nanoplankton replaced netplankton as the dominant phytoplankton group in the surface layer (see Figure 7). On the slope, bottom layer chlorophyll was reduced to zero at the southern and eastern portion of the slope due to high ingestion, a lack of netplankton in the upper layers for recruitment via sinking, and reduced mixing inhibiting exchange across the pycnocline. The slope bloom decreased due to the very large $(>100 \%$ of primary production) grazing/ingestion at this time.

\subsection{Optical/Biological Coupling}

The interaction between optical and biological processes was partially obscured by the dramatic effects of the coupling between physical and biological events. Optical/ biological effects occurred on much larger space and time scales (i.e., regional and weekly/monthly) than the physical/ biological interactions, which manifested themselves on pixel $(\approx 5 \mathrm{~km})$ and $3-15$ day scales. Nevertheless, optical processes were critical in determining the primary production realized by the model. The lower optical thickness of the slope region, due to reduced amounts of chlorophyll, gelbstoff, and detritus, allowed deeper light penetration. This fact, along with higher temperatures and subsequent higher growth rates, was responsible for higher primary production on the slope despite lower biomasses. On the coast, greater optical thickness due to greater concentrations of these optical properties reduced light penetration and delayed the exhaustion of nutrients by restricting primary production.

The atmospheric and oceanic radiative transfer models produced more realistic values of the available irradiance in the water column by spectrally attenuating light in both fluids, which occurs in nature. The spectral models changed not only the spectral quality of the light at depth, but also the total amount and the depth distribution of the light. In the absence of chlorophyll, the spectral models produced as much as $43 \%$ less light in the surface layers $(<10 \mathrm{~m})$ and $61 \%$ more light in the deeper layers as compared to a nonspectral attenuation model derived from the same light penetration data (Figure 4). These percent differences translated into very large differences in the total irradiance. A nonspectral, or really spectrally averaged, downwelling attenuation coefficient $K_{\text {PAR }}$ cannot simultaneously account for the high attenuation in the red wavelengths and low attenuation in the blue by water alone. Addition of spectral chlorophyll attenuation created even greater discrepancies (see Figure 4). Bear in mind the two models converged in the computation of the $1 \%$ light depth and were both regionally dependent. Use of a single $K_{\text {PAR }}$ to represent the diverse regions of the MAB would produce even worse results.

The net result of the nonspectral model is an overestimate of the available quanta at the depths where most phytoplankton growth occurs. Since phytoplankton growth is intimately tied to the light available at depth, nonspectral models produce inaccurate estimates of primary production.

\subsection{Phytoplankton Group Distributions}

The resultant distribution of the two phytoplankton groups, with netplankton dominating the total phytoplankton on the coast and nanoplankton on the slope (Figure 7), was one of the most unambiguous results of this modeling effort. The results showed that at least two phytoplankton groups are required in order to realistically simulate the phytoplankton dynamics in a region as diverse as the MAB. Furthermore, the computed distribution of phytoplankton groups agrees with both theory and observation [Malone et al., 1983a; O'Reilly et al., 1987].

These results suggest that the model incorporated a physical/biological mechanism to explain these observed distributions in the MAB. The mechanism involves the interaction between mixing, differential sinking rates, and differential growth rates. Netplankton grew faster than nanoplankton in the model, as has been observed in situ [Malone, 1982; Walsh et al., 1987]. Without sinking, they will dominate the total phytoplankton in all regions, as was observed in a test where no sinking or mixing was allowed. But they also sank faster, due mostly to their larger size and Stokes' settling law considerations. Without mixing, then, nanoplankton gained an advantage over netplankton because the latter tended to sink out of the euphotic zone, in spite of the fact that nanoplankton grew more slowly. In shallow areas of the model, however, mixing counteracted the tendency of netplankton to sink out of the euphotic zone and kept them suspended so that they could utilize their higher growth rates to outcompete nanoplankton for nutrients and photons and 
dominate the total phytoplankton. This can be seen clearly in the figures of primary production (Figure 8) and relative abundance (Figure 7), showing increases in netplankton relative to nanoplankton during high mixing periods and decreases during low. Mixing thus acted as a source of netplankton to the euphotic zone and a stimulator of primary production in the shallower areas of the model, i.e., $<60 \mathrm{~m}$.

On the slope, however, netplankton sank through the 200-m pycnocline. Thus they were lost to the model domain and could not be recovered through resuspension. This allowed the slower-growing nanoplankton to dominate purely because of their lower sinking rates. Losses of netplankton through the slope pycnocline averaged about $\approx 0.5 \mathrm{mg}$ chlorophyll $\mathrm{m}^{-2} \mathrm{~d}^{-1}$, which over the $2.8 \times 10^{4} \mathrm{~km}^{2}$ slope area, and assuming a carbon to chlorophyll ratio of $50: 1$, resulted in a loss of 700 metric tons $\mathrm{C} \mathrm{d}^{-1}$, or about $13 \%$ of the daily netplankton primary production on the slope. This contrasted with a mean nanoplankton loss of $\approx 0.05 \mathrm{mg}$ chlorophyll $\mathrm{m}^{-2} \mathrm{~d}^{-1}$, or 70 metric tons $\mathrm{C} \mathrm{d}^{-1}$, or an order of magnitude less, representing $<1 \%$ of the daily nanoplankton primary production.

Even without losses through the pycnocline, sinking of netplankton in deep water took them out of range to be resuspended into the euphotic zone in substantial amounts except under rare high mixing events. This may be noted on the outer shelf where nanoplankton also dominated, although less so than on the slope (Figure 7). That they dominated less here was because a source of netplankton existed at the bottom, unlike over the slope, which could be resuspended under high mixing events.

Whereas mixing acted as a source of netplankton to the euphotic zone, it acted as a sink for nanoplankton. Because of their very low sinking rates, nanoplankton tended to form top-heavy vertical distributions. As nanoplankton were mixed, their redistribution was downward into lower light environments, thus reducing their growth and abundance. Quiescent periods allowed them to remain in the euphotic zone longer and grow. This can also be seen in the figures of primary production and relative abundance (Figures 8 and 7). During the maximum wind/mixing event of approximately April 10, nanoplankton primary production and percent abundance decreased on the slope while in the calmer periods preceding and following, their production and relative abundance increased.

A series of calmer wind periods toward the end of April to early May resulted in a net increase in nanoplankton relative to netplankton, particularly in the midshelf (Figure 7). This suggests that the interaction between turbulence, sinking, and growth rates can provide a mechanism to explain the often noted [e.g., O'Reilly et al., 1987; Walsh et al., 1987] seasonal succession of phytoplankton in spring from netplankton-dominated communities to nanoplankton-dominated communities. To test this, we allowed the model to run until the end of May 1979, under wind conditions again from JFK Airport. In fact, nanoplankton did overtake netplankton as the dominant group by about May 15 . The end relative abundances were about $58: 42$ (\%) nanoplankton to netplankton.

The interesting point is that a reasonable simulation of seasonal phytoplankton group succession was achieved in a model that contained no buoyancy forcing, and hence no seasonal density stratification, which is thought to be the key factor initiating such succession [Malone and Chervin, 1979;
Malone et al., 1983b]. Results in the present model showed that a reduction in total water column mixing due to reduced winds in late spring can induce the necessary conditions for seasonal succession without stratification.

\subsection{Primary Production}

Except for the outer shelf, computed primary production was within reasonable agreement with observations both for the time and location of the model, and for long-term means. Considering the redistribution of netplankton and nanoplankton across regions in the model, these results suggest that the model reproduced the mechanisms responsible for primary production in the MAB, and accounted for variability due to regional differences in physics.

These regional trends in primary production disagreed with those of chlorophyll biomass, the low biomass slope region exhibiting the largest primary production and the high biomass coast exhibiting relatively low production. This suggests that inclusion of physical, biological, and optical variables, as in the model, is required to adequately estimate primary production in diverse regions. Primary production models that use only satellite-derived chlorophyll as an independent variable [e.g., Smith et al., 1982; Balch et al., $1989 a$ ] neglect important variables that affect primary production, and can only apply over discrete regions or times. This may help explain the low coefficients of determination in such models [see Balch et al., 1989a]. A model such as the present one, which includes the dominant variables affecting primary production and the interactions among these variables, can be used in conjunction with satellite observations to provide a better evaluation of primary production.

\subsection{Region-by-Region Synopsis}

4.5.1. Coast. Computed horizontal and vertical trends of chlorophyll on the coast compared generally favorably with CZCS estimates, and computed vertical trends of chlorophyll, nitrate, and ammonium appeared to match ship observations. In addition, primary production values were in excellent agreement with those determined for March 1979 as well as those from a longer time series for March-April. The region responded quickly and unequivocally to wind events: The direction of the wind initiated upwelling and downwelling events, and the speed of the wind induced variations in mixing.

Seasonal scale phytoplankton dynamics on the coast were driven by nutrient and light availability: Increases in abundance paralleled the seasonal increase in light until nutrients were exhausted, then abundances decreased, a classic spring bloom pattern. These results encourage reliance on the model and, coupled with the favorable comparisons with CZCS estimates and ship observations, suggest that the model may be used to predict chlorophyll, nitrate, ammonium, and phytoplankton group distributions here as a result of external forcings, requiring perhaps only a change in initial values. This is a very valuable result, since it is in the coast region that effects of perturbations on the ocean system are most likely to directly affect human populations.

4.5.2. Midshelf. The mean of computed chlorophyll on the midshelf compared favorably to CZCS estimates, but tended to underestimate in March and overestimate in May. 
Computed primary production, although slightly low in March and high in April, was not in great disagreement with either spring 1979 measurements or long-term observations, and a simple adjustment of the assumed carbon to chlorophyll ratio might produce better agreement. Malone et al. [1983a] suggested that the carbon to chlorophyll ratio may vary from $\approx 40$ to 150 , depending on species composition. An exponential grazing/ingestion function, as used on the outer shelf and slope, might be more appropriate for the midshelf than the constant function used here. Such an ingestion function would allow more growth in March, and thus higher concentrations and primary production, and less in late April, more in line with CZCS estimates and ship observations. This would also reduce nitrate concentrations in March, producing better agreement with observations.

A discrepancy between the computed chlorophyll and CZCS estimates occurred in early May when the model showed a prominent midshelf maximum that was not as apparent in the CZCS imagery. There is a good physical reason for the midshelf maximum as it occurred in the model, first noted by Walsh [1980]. Shoreward of $\approx 30 \mathrm{~m}$, nitrate became quickly exhausted, preventing substantial growth and accumulation of biomass. Seaward of $\approx 60 \mathrm{~m}$, the bottom depth was too great to allow substantial resuspension of netplankton except during high wind events, which did not occur in late April/early May. Furthermore, nanoplankton in the upper layers of the outer shelf were heavily grazed/ingested at this time of year. Only at midshelf did sufficient nutrients and low enough grazing/ingestion exist to allow accumulation of chlorophyll biomass, which, it may be noted, was beginning to become predominantly nanoplankton.

4.5.3. Outer shelf. Computed first attenuation depth magnitudes and relatively featureless horizontal trends of chlorophyll were in very good agreement with CZCS estimates on the outer shelf. Observed vertical trends of $\mathrm{NO}_{3}$ and $\mathrm{NH}_{4}$ in March were also in good agreement with the model. However, computed chlorophyll biomasses substantially underestimated ship surface observations in this region for March (by about $4 \mathrm{mg} \mathrm{m}^{-3}$ ) and late April/early May (by about $2 \mathrm{mg} \mathrm{m}^{-3}$ ). These large observed chlorophyll biomasses explained the high measured primary production here, also in disagreement with that computed.

Computed biomasses and primary production (and presumably satellite-estimated chlorophyll) resulted from critical depth considerations: The water depth here was too deep to allow resuspension of netplankton except under high mixing events. More buoyant nanoplankton, however, were unable to dominate the total phytoplankton here as much as on the slope because occasional high mixing events provided a source of fast-growing netplankton, unlike the slope where sinking netplankton were lost to the model domain. Such a scenario is plausible, and the high observed chlorophyll values require an alternative explanation.

The explanation could be the existence of the strong and persistent shelf break density front [Houghton et al., 1988]. Ryther and Yentsch [1958], Malone et al. [1983a], and Marra et al. [1990] all found large chlorophyll concentrations on the outer shelf, which they attributed to this density front.

However, no outer shelf chlorophyll maximum was observed in the 11 CZCS images available for spring 1979. A possible explanation for this discrepancy between in situ and satellite observations includes local optical irregularities, confounding the water-leaving radiance ratio methods used in the CZCS biooptical algorithms to estimate chlorophyll. For instance, if the large observed chlorophyll biomasses were due to coccolithophore blooms, scattering of light by associated detached coccoliths might lead to an underestimate of derived chlorophyll values [Holligan et al., 1983; Morel, 1987]. Coccolithophores were observed in substantial abundance in this region by Malone et al. [1983a]. However, Balch et al. [1989b] suggested that detached coccoliths may actually cause chlorophyll to be overestimated under some circumstances.

Another possibility might arise by the existence of phycoerythrin-containing cyanobacteria on the outer shelf. Strong light absorption at $550 \mathrm{~nm}$ by phycoerythrin [Jeffrey, 1980] would increase the water-leaving radiance ratio of 443 to 550 $\mathrm{nm}$ used to derive CZCS chlorophyll [see Gordon et al., 1983], and produce an underestimate of the actual chlorophyll. Both this scenario and the one involving coccolithophores, however, requires an explanation for the occurrence of these organisms on the outer shelf and not elsewhere on the MAB, an explanation which is elusive.

Finally, ship observations may reflect subgrid, subpixel scale phenomena, i.e., the observations are real but are aliased [Walsh et al., 1987]. A third cruise in 1979, by the R/V Kelez (April 17-26), showed very low chlorophyll values on the outer shelf. Long-term observations in the MAB by $O$ 'Reilly et al. [1987] also conformed to the results of this study.

4.5.4. Slope. The domination of the slope region by nanoplankton was a persistent feature of the model, and, considering the strong support for such phytoplankton distribution in observations [O'Reilly et al., 1987], the results suggest that the model contains the proper dynamics forcing this distribution. In addition, the computed top-heavy vertical distributions of chlorophyll were well supported by observations here, especially in late April. The success of the model in matching horizontal trends in CZCS imagery and observed vertical trends in chlorophyll, as well as observed primary production, is encouraging.

\section{ConcLusion}

The coupled physical/biological/optical model appeared to reasonably well simulate the mesoscale, subtidal features of spring 1979 phytoplankton dynamical system in the MidAtlantic Bight. Computed chlorophyll concentrations in the first attenuation depth were within 1 standard deviation agreement of those estimated by the CZCS on a regional basis, except on the coast. Two phytoplankton groups, which differed in maximum growth rates, sinking rates, and specific spectral absorption, were initiated at equal distributions throughout the model domain, and organized during the course of the model run into distributions across regions that conformed to long-term observations in the MAB. These results suggested that the coupling of physical, biological, and optical processes can provide an adequate representation of the gross features of the spring phytoplankton dynamical system. Furthermore, inclusion of more than one phytoplankton group is necessary to describe distributions in physically diverse regions, such as the MAB.

The success of the model in simulating these processes gave rise to reasonable estimates of regional scale primary production, even in the MAB's physically diverse regions. 
Thus, the model appeared to be useful for estimating largescale primary production and for examining the interactions between physics and biology causing variations in production and phytoplankton group distributions. The model can thus serve as a basis for developing more sophisticated models from which we may eventually be able to predict variations in primary production and the marine ecosystem.

Acknowledgments. We wish to thank Otis B. Brown and Robert H. Evans at the Rosenstiel School of Marine and Atmospheric Sciences at the University of Miami for providing the CZCS images and for their expertise in the analysis of the images. We also would like to thank Dwight $A$. Dieterle for software assistance and for many illuminating discussions on the scientific aspects of the study. This research was supported by NASA grant NAGW-678 and DOE grant DE-FG05-85ER60285.

\section{REFERENCES}

Aas, E., The Refractive Index of Phytoplankton, Inst. Geofys. Ref. 46, 61 pp., Univ. of Oslo, Oslo, 1981.

Baker, K. S., and R. C. Smith, Bio-optical classification and model of natural waters, 2, Limnol. Oceanogr., 27, 500-509, 1982.

Balch, W. M., M. R. Abbott, and R. W. Eppley, Remote sensing of primary production, 1 , A comparison of empirical and semianalytical algorithms, Deep Sea Res., 36, 281-295, $1989 a$.

Balch, W. M., R. W. Eppley, M. R. Abbott, and F. M. H. Reid, Bias in satellite-derived pigment measurements due to coccolithophores and dinoflagellates, J. Plankton Res., 11, 575-581, $1989 \mathrm{~b}$.

Beardsley, R. C., and W. C. Boicourt, On estuarine and continental shelf circulation in the Middle Atlantic Bight, in Evolution of Physical Oceanography, edited by B. A. Warren and C. Wunsch, pp. 189-233, MIT Press, Cambridge, Mass., 1981.

Beardsley, R. C., D. C. Chapman, K. H. Brink, S. R. Ramp, and R. Schlitz, The Nantucket Shoals Flux Experiment (NSFE79), I, a basic description of the current and temperature variability, $J$. Phys. Oceanogr., 15, 713-748, 1985.

Bricaud, A., A. Morel, and L. Prieur, Absorption by dissolved organic matter of the sea (yellow substance) in the UV and visible domains, Limnol. Oceanogr., 26, 43-53, 1981.

Campbell, J. W., and J. E. O'Reilly, Role of satellites in estimating primary productivity on the northwest Atlantic continental shelf, Cont. Shelf Res., 8, 179-204, 1988.

Csanady, G. T., Mean circulation on shallow seas, J. Geophys. Res., 81, 5389-5399, 1976.

Csanady, G. T., and P. Hamilton, Circulation of slopewater, Cont. Shelf Res., 8, 565-624, 1988.

Dagg, M. J., and J. T. Turner, The impact of copepod grazing on the phytoplankton of Georges Bank and New York Bight, Can.J. Fish. Aquat. Sci., 39, 979-990, 1982.

Falkowski, P. G., C. N. Flagg, G. T. Rowe, S. L. Smith, T. E. Whitledge, and C. D. Wirick, The fate of a spring phytoplankton bloom: Export or oxidation?, Cont. Shelf Res., 8, 457-484, 1988.

Gordon, H. R., and W. R. McCluney, Estimation of the depth of sunlight penetration in the sea for remote sensing, Appl. Opt., 14, 413-416, 1975.

Gordon, H. R., D. K. Clark, J. W. Brown, O. B. Brown, R. H. Evans, and W. W. Broenkow, Phytoplankton pigment concentrations in the Middle Atlantic Bight: Comparison of ship determinations and CZCS estimates, Appl. Opt., 22, 20-36, 1983.

Gregg, W. W., and K. L. Carder, A simple spectral solar irradiance model for cloudless maritime atmospheres, Limnol. Oceanogr., $35,1657-1675,1990$.

Han, G. C., D. V. Hansen, and J. A. Galt, Steady state diagnostic model of the New York Bight, J. Phys. Oceanogr., 10, 1998-2020, 1980.

Holligan, P. M., M. Viollier, D. S. Harbour, P. Camus, and M. Champagne-Philippe, Satellite and ship studies of coccolithophore production along a continental shelf edge, Nature, 304, 339-341, 1983.

Hopkins, T. S., and D. A. Dieterle, An externally forced barotropic circulation model for the New York Bight, Cont. Shelf Res., 2, 49-73, 1983.

Hopkins, T. S., and D. A. Dieterle, Analysis of the baroclinic circulation in the New York Bight with a 3-d diagnostic model, Cont. Shelf Res., 7, 237-265, 1986.
Hopkins, T. S., and L. A. Slatest, The vertical eddy viscosity in the presence of baroclinic flow in coastal waters, J. Geophys. Res., $9 I, 14,269-14,280,1986$.

Houghton, R. W., F. Aikman, and H. W. Ou, Shelf-slope frontal structure and cross-shelf exchange at the New England shelfbreak, Cont. Shelf Res., 8, 687-710, 1988.

Ishizaka, J., Coupling of Coastal Zone Color Scanner data to a physical-biological model of the southeastern U.S. continental shelf ecosystem, 2, An Eulerian model, J. Geophys. Res., 95, 20,183-20,200, 1990.

Jeffrey, S. W., Algal pigment systems, in Primary Productivity in the Sea, edited by P. G. Falkowski, pp. 33-57, Plenum, New York, 1980.

Johnson, D. R., Nearshore surface currents in the Chesapeake Bight during summer, Cont. Shelf Res., 7, 367-378, 1987.

Kiefer, D. A., and J. B. SooHoo, Spectral absorption by marine particles of coastal waters off Baja California, Limnol. Oceanogr., 27, 492-299, 1982.

Malone, T. C., Phytoplankton photosynthesis and carbon specific growth: Light-saturated rates in a nutrient rich environment, Limnol. Oceanogr., 27, 226-235, 1982.

Malone, T. C., and M. B. Chervin, The production and fate of phytoplankton size fractions in the plume of the Hudson River, New York Bight, Limnol. Oceanogr., 24, 683-696, 1979.

Malone, T. C., T. S. Hopkins, P. G. Falkowski, and T. E. Whitledge, Production and transport of phytoplankton biomass over the continental shelf of the New York Bight, Cont. Shelf Res., I, 305-337, 1983a.

Malone, T. C., P. G. Falkowski, T. S. Hopkins, G. T. Rowe, and T. E. Whitledge, Mesoscale response of diatom populations to a wind event in the plume of the Hudson River, Deep Sea Res., 30 , 149-170, $1983 b$.

Marra, J., R. W. Houghton, and C. Garside, Phytoplankton growth at the shelf-break front in the Middle Atlantic Bight, J. Mar. Res., 48, 851-868, 1990.

Marshall, H. G., and M. S. Cohn, Phytoplankton distribution along the eastern coast of the USA, VI, Shelf waters between Cape Henry and Cape May, J. Plankton Res., 9, 139-149, 1987.

Morel, A., Chlorophyll-specific scattering coefficient of phytoplankton, a simplified theoretical approach, Deep Sea Res., 34, 1093$1105,1987$.

Nagle, C. M., Climatology of Brookhaven National Laboratory, 1974 through 1977, Rep. BNL-50857 UC-11, Environ. Control Technol. Earth Sci., Brookhaven Natl. Lab., Upton, N. Y., 1978.

O'Reilly, J. E., C. Evans-Zetlin, and D. A. Busch, Primary production, in Georges Bank, edited by R. H. Backus and D. W. Bourne, pp. 220-233, MIT Press, Cambridge, Mass., 1987.

Ryther, J. H., and C. S. Yentsch, Primary production of continental shelf waters off New York, Limnol. Oceanogr., 3, 327-335, 1958.

Sathyendranath, S., L. Lazzara, and L. Prieur, Variations in the spectral values of specific absorption of phytoplankton, Limnol. Oceanogr., 32, 403-415, 1987.

Smith, R. C., and K. S. Baker, Optical classification of natural waters, Limnol. Oceanogr., 23, 260-267, 1978.

Smith, R. C., R. W. Eppley, and K. S. Baker, Correlation of primary production as measured aboard ship in Southern California coastal waters and as estimated from satellite chlorophyll images, Mar. Biol., 66, 281-288, 1982.

Smith, S. L., and P. V. Lane, Grazing of the spring diatom bloom in the New York Bight by calanoid copepods, Calanus finmarchicus, Metridia lucens, and Centropages typicus, Cont. Shelf Res., $8,485-510,1988$.

Steele, J. H., Environmental control of photosynthesis in the sea, Limnol. Oceanogr., 7, 137-150, 1962.

von Bock, K., Atlantic Coastal Experiment V, FRV IV cruise (MESEX I), 15-24 March 1979 data report, Rep. BNL 33394, 249 pp., Brookhaven Natl. Lab., Upton, N. Y., 1983a.

von Bock, K., Atlantic Coastal Experiment 5, R/V Advance II cruise (MESEX I), 27 April-2 May 1979 data report, Rep. BNL 33393, 155 pp., Brookhaven Natl. Lab., Upton, N. Y., $1983 b$.

Walsh, J. J., Shelf-sea ecosystems, in Analysis of Marine Ecosystems, edited by A. R. Longhurst, pp. 159-196, Academic, San Diego, Calif., 1980.

Walsh, J. J., D. A. Dieterle, and W. E. Esaias, Satellite detection of phytoplankton export from the Mid-Atlantic Bight during the 1979 spring bloom, Deep Sea Res., 34, 675-703, 1987. 
Walsh, J. J., D. A. Dieterle, and M. B. Meyers, A simulation analysis of the fate of phytoplankton within the Mid-Atlantic Bight, Cont. Shelf Res., 8, 757-788, 1988.

Wroblewski, J. S., A model of the spring bloom in the North Atlantic and its impact on ocean optics, Limnol. Oceanogr., 34, 1563-1571, 1989.

W. W. Gregg, NASA Goddard Space Flight Center, Code 936, Greenbelt, MD 20771.
J. J. Walsh, Department of Marine Science, University of South Florida, St. Petersburg, FL 33701.
(Received March 19, 1990; revised April 24, 1991; accepted September 4, 1991.) 